\title{
'If men were angels, no government would be necessary': the intuitive theory of social motivation and preference for authoritarian leaders
}

\author{
Daniel Nettle $1^{1^{*}}$ \\ Rebecca Saxe ${ }^{2}$
}

1. Population Health Sciences Institute, Newcastle University, Newcastle UK

2. Department of Brain and Cognitive Sciences and McGovern Institute for Brain Research, Massachusetts Institute of Technology, Cambridge, MA, USA

To whom correspondence should be addressed: daniel.nettle@ncl.ac.uk

\begin{abstract}
We postulate that at least two distinct cognitive systems affect political judgements. The first system, moral cognition, delivers intuitions about what societal outcomes would be ideal. The second system, which we dub the intuitive theory of social motivation, makes predictions about how other citizens will behave in practice, and hence feeds into opinions on how their conduct should be regulated. Both systems are situation sensitive. We illustrate this thesis through a study of intuitions about redistribution and governance. We present four experiments in which 750 U.K. adults prescribed ideal levels of redistribution for hypothetical societies under different circumstances, and predicted what level of redistribution those societies would actually be able to achieve. Participants judged that the level of redistribution societies would achieve was lower than the ideal. The gulf was particularly large for societies facing war or scarcity, because a subset of people was predicted to respond selfishly to these threats. Strong, authoritarian leaders were seen as more desirable in these circumstances. Specifically, this was because citizens facing these threats were predicted to become less amenable to rational persuasion and their inherent moral sense, and more amenable to control through harsh punishment, which is what strong leaders can deliver. We complement our experimental results with an analysis of World Values Survey data from 52 countries, showing that authoritarian governance preferences are positively associated with the perceived threat of war, and negatively associated with per capita GDP, a proxy for the abundance of resources.
\end{abstract}

Key words: redistribution, authoritarianism, morality, political cognition, World Values Survey 


\section{Introduction}

There are two central components to political cognition: beliefs about what resources members of society should be entitled to; and beliefs about how the behaviour of members of society is best regulated. This paper links the two, by examining what factors affect preferences for redistribution on the one hand, and preferences for authoritarian leadership on the other. Specifically, our work addresses the generalization that preference for authoritarian leadership is increased by threats to society. It is well understood that this is the case, but less well understood why. We argue that answering the why question requires us to understand what people think ought to happen in times of societal threat; what people think will actually happen; and what kinds of interventions will be effective at reducing the gap between the two.

We postulate that preferences about redistribution, and entitlement to resources more generally, are outputs of moral psychology, whilst preferences about authority, and regulation of behaviour more generally, are also affected by a separate cognitive system we dub the intuitive theory of social motivation (following McClintock's (1972) definition of social motivation). Moral psychology outputs prescriptions about what people should do, whereas the intuitive theory of social motivation outputs predictions about what they will do, which might not be the same. Both moral psychology and the intuitive theory of social motivation are fundamentally situation sensitive. That is, they both take as inputs features of the societal situation (who are the people, what are they trying to do, what ecological and social pressures do they face?), and return different outputs (prescriptions or predictions) as these features vary. A corollary of this is that neither moral views nor authoritarianism are stable traits of individuals, the same individual instead capable of quite different conclusions for different situations. We will explore this situation sensitivity through a series of within-subjects experiments where we vary key situational features, and measure how both the ideal level of redistribution, and preference for authoritarian governance, vary in response.

We build on our earlier work (Nettle \& Saxe, 2020) in which we studied preferences for redistribution in UK adults using a 'hypothetical societies' methodology (see also Jetten et al., 2015; Sprong \& Jetten, 2019). Brief vignettes described salient features of hypothetical societies, and we measured the level of redistribution participants considered ideal for each one. The point of the method is not the realism of the vignettes: rather it is the potential to expose the cognitive operations that determine redistribution preferences by parametrically varying the input information in minimal and unambiguous ways. We found that favoured levels of redistribution were additively affected by four situational features: luck (higher redistribution favoured where the initial distribution of resources was more affected by chance); heterogeneity (higher redistribution favoured for more homogeneous groups); war (higher redistribution favoured in wartime); and scarcity (lower redistribution favoured when resources are scarce). These results were consistent with evidence from studies using different methodologies that redistribution preferences respond rapidly to changing actual or appraised societal situations (Aaroe \& Petersen, 2014; Almås et al., 2020; Kasza, 2006; Nettle et al., 2021; Obinger \& Schmitt, 2019; Piff et al., 2020). Participants' preferences for a level of redistribution carried high levels of moral conviction, justifying our assumption that judgements about who in society is entitled to what are primarily outputs of moral psychology.

As an ancillary outcome variable in two experiments of Nettle and Saxe (2020), we asked participants to rate the likely severity of a number behaviours that undermine redistribution, such as people over-claiming from the system or failing to pay in (in short, people failing to comply with the moral obligations defined in the redistributive system). Judgements about these likely problems were independent of judgements about how much redistribution there should ideally be. For one of 
the situational features, war, participants felt it should ideally increase redistribution, but would actually make all the problem behaviours worse. It was this finding that gave rise to our contention, in the present paper, that intuitions about how people will behave in a given situation are governed by a cognitive system independent of the one that generates intuitions about how they ought to behave. Relatedly, we suggest that the amount of redistribution people judge to be achievable, which will depend on intuitions about compliance with such a system in practice, might be somewhat independent of the amount of redistribution that people judge to be ideal, which is a moral judgement. This distinction could be important for the puzzle of why voters are sometimes sceptical of redistributive policies even when the benefits of those policies seem clear.

Our finding that more severe problems of redistribution were anticipated in threatening situations such as war linked to a longstanding literature on authoritarianism and punishment. A varied set of studies has shown that authoritarian leaders, and tight punitive regulation of individual behaviour, are more strongly favoured in situations where society is perceived to face threats to its existence (Caluori et al., 2020; Doty et al., 1991; Duckitt \& Fisher, 2003; Feldman \& Stenner, 1997; Jackson et al., 2020; Kakkar \& Sivanathan, 2017; Laustsen \& Petersen, 2015; Little et al., 2012), and/or where social coordination is felt to be breaking down or likely to break down (Sprong \& Jetten, 2019). We suggest this may be because, under certain kinds of societal threat, the outputs of moral cognition and of the intuitive theory of social motivation are strongly disjunct (for example, people should be more cooperative, but some will be more selfish, as in the war example above). Strong leaders and punitive regulation would thus be experienced as desirable in exactly these situations, as long as people believe that dominance and punishment are effective interventions to address them.

Previous work has shown people to be generally pessimistic about the moral behaviour of others (compared to themselves; Klein \& Epley, 2016). Our notion of an intuitive theory of social motivation goes beyond just a blanket negative prior about people's level of morality. Rather, our claim is that people spontaneously adjust their predictions about others' behaviour according to the circumstances those others face. This inferential ability extends to people they do not know and circumstances of which they have no direct experience. Moreover, they will be able to prescribe suitable interventions to regulate others' behaviour, even in novel situations. Predictive and interventional generativity are hallmarks of intuitive theories (Gerstenberg \& Tenenbaum, 2017). The present research does not fully characterise participants' intuitive theory of social motivation, but it does begin to map them by examining, within the hypothetical societies framework, how situational features affect expectations about the behaviour of members of society, and prescriptions about how their behaviour should be governed.

In the present paper, we present four experimental studies with UK participants (studies 1 and 3-5) and one cross-national correlational study (study 2). The experimental studies use variants of Nettle and Saxe's (2020) within-subjects methodology, again varying all or a subset of the four situational features luck, heterogeneity, war and scarcity. Our dependent variables fall into two sets. First, as in Nettle and Saxe (2020), we measure participants' judgements of the ideal level of redistribution. We are interested in this variable both intrinsically, and because it is a representative example of a moral judgement. Second, we measure participants' expectations of how members of the society will behave, and how their behaviour should be regulated. We use three measures: how much redistribution will actually be achieved (which can be directly compared to the ideal level), how morally people will behave in general, and how authoritarian the government would need to be. We postulate that these three variables are the direct (in the former two cases) and indirect (in the latter case) outputs of the intuitive theory of social motivation. 
At the most general level, our first hypothesis is that the situational features will affect both moral prescriptions and predictions about human behaviour, but will do so independently. That is, the effects of varying the situational features on ideal redistribution will be decoupled from, and possibly in opposite directions to, the effects on achievable distribution and general moral behaviour. Those two dependent variables should be expected to move in lock-step: features that reduce expected moral behaviour will reduce achievable redistribution. Our second hypothesis is that authoritarian governance preference will be increased by those situations that bring about low expected moral behaviour; hence expected authoritarian governance preference and expected moral behaviour will be inversely associated.

More specific predictions for each situational feature and study are explained in the study-by-study presentation. The generic features of the experimental methods are explained in the Methods section of study 1 , allowing subsequent Methods sections to be brief and only mention differences from study 1.

\section{Study 1}

Study 1 tested the effects of the four situational features (luck, heterogeneity, war and scarcity) used in Nettle and Saxe's (2020) paper. We note that these are not the only possible situational features that could affect either moral judgement or intuitions about likely behaviour: disease, mortality risk, demography and many others could also do so. The selection of these features for the earlier paper was initially based on prior literature concerning support for redistribution. We retain them here for continuity with the earlier work, acknowledging that other features could and should be studied in due course.

Building on Nettle and Saxe (2020), we described eight hypothetical villages, the descriptions varying by one specific piece of situational information. The descriptions formed four minimal pairs, one pair for each of the four features. Comparing the outcome variables between the two members of the pair thus tested our hypotheses regarding the effects of each feature. Our outcome variables were the ideal redistribution of Nettle and Saxe (2020), plus new measures of achievable redistribution, the expected moral behaviour of the villagers, and preference for authoritarian governance in the village. Our predictions were derived from Nettle and Saxe (2020), from prior literature on societal threat and authoritarianism, and from the arguments outlined in the General Introduction.

\section{Methods}

Pre-registration

Design and predictions for study 1 were pre-registered prior to data collection at https://osf.io/rbfxs/.

\section{Participants}

Study 1 participants ( $n=301,151$ men, 150 women) were recruited from online research participation platform www.prolific.co. Mean age was 28.73 years (sd 10.62). Participant compensation for this and subsequent studies exceeded the UK national living wage given the length of the study. All participants were UK nationals and residents. We pre-registered a target sample size of 300. Most of our predictions were logically equivalent to paired t-tests (e.g. comparing the high versus low luck village for ideal redistribution). Assuming a smallest effect size of interest of $d=0.2$ (Cohen, 1988), 300 participants provides better than $90 \%$ power ( $\alpha=0.05$, two-sided) for testing each of these predictions. 


\section{Design and materials}

The study used a within-subjects design in which all participants rated eight villages. These formed four minimal pairs with respect to the four situational features of interest. This design differs from Nettle and Saxe's (2020) full-factorial design (which would require sixteen villages for four features). However, the experimental effects in Nettle and Saxe (2020) were all additive, suggesting that each feature can be studied in isolation from the others. Moreover, we piloted the present methodology with the Nettle and Saxe's (2020) original dependent variable and largely replicated their experimental effects (see https://osf.io/q53dw/ for that pilot study).

Participants first saw generic information as follows:

We are considering a series of different villages in a distant country that you are never likely to visit. There are some things that are true about all the villages we are going to consider. In each village, the villagers live by growing food in their gardens. Every villager has a garden and all the gardens are equal in size. Each villager gets a harvest from their garden every year.

After the harvest each year, every villager is obliged to place a certain proportion of their harvest into a common store. This proportion is the same for every villager. Whatever is left after the specified proportion has been paid into the common store is kept by the grower for their own use. The food in the common store is shared out among all the villagers.

This generic information was followed by the village-specific information, followed by the dependent measures, for each village.

Independent variables. The eight specific statements that constituted the eight villages are shown in table 1.

Table 1. Village-specific information for the eight experimental villages.

\begin{tabular}{|l|l|}
\hline Condition & Statement \\
\hline Luck & $\begin{array}{l}\text { The sizes of people's harvests in this village are mainly determined by } \\
\text { luck, because there are insects and plant diseases that strike at } \\
\text { random. }\end{array}$ \\
\hline Effort & $\begin{array}{l}\text { The sizes of people's harvests in this village are mainly determined by } \\
\text { how much effort they put in. }\end{array}$ \\
\hline Hoterogeneity & $\begin{array}{l}\text { The villagers in this village are rather different from one another in } \\
\text { terms of beliefs, customs and appearance. }\end{array}$ \\
\hline War & $\begin{array}{l}\text { The villagers in this village are all very similar to one another in terms } \\
\text { of beliefs, customs and appearance. }\end{array}$ \\
\hline Peace & This village is currently at war with a neighbouring village. \\
\hline Scarcity & This village is at peace with all of the neighbouring villages. \\
\hline Abundance & $\begin{array}{l}\text { In this village, land and resources are scarce. There is only just enough } \\
\text { for everyone's basic needs over all. }\end{array}$ \\
\hline & $\begin{array}{l}\text { In this village, land and resources are abundant. There is more than } \\
\text { enough for everyone's basic needs over all. }\end{array}$ \\
\hline
\end{tabular}

Dependent measures: Redistribution. After each village-specific statement, there followed the response items for ideal an achievable redistribution, with sliders from $0 \%$ (nothing) to $100 \%$ (their whole harvest): 
In this village, what proportion of their harvests should villagers ideally pay into the common store?

In this village, what proportion of the harvests will, in practice, get put into the common store and then shared out, given what you know about social motivation?

Dependent measures: Expected moral behaviour. The expected moral behaviour of villagers was measured by rating the truth of four statements (two reverse scored), with responses on a 100-point slider from strongly. Responses were averaged. Cronbach's $\alpha$ was 0.81 .

1. Villagers will follow the rules.

2. Each villager will think mainly of him/herself $(R)$.

3. Villagers will do what is morally right.

4. Villagers will try to exploit the common store system to their own advantage (R).

Dependent measures: Authoritarian governance preference. Authoritarianism has been parsed into three sub-components (Duckitt et al., 2010): desire for leaders to be strong and aggressive (authoritarian aggression), for non-leaders to be made to submit (conservatism), and for conventions to be enforced strictly (traditionalism). We measured each component with two items measured on 100-point scales from strong disagree to strongly agree (one item scored in each direction), providing a six-item scale over all. The items were adapted from Duckett et al. (2010). Responses were averaged. Cronbach's $\alpha$ was 0.62 .

1. The village should have strong, tough leaders.

2. People who break the rules of the village need to be treated with leniency and kindness (R).

3. The villagers need to preserve their traditional values.

4. Everyone in this village should be free to pursue his or her own lifestyle (R).

5. Villagers must be obedient to their leaders.

6. Villagers should be allowed to question and challenge decisions they do not like (R).

Individual difference measures. We measured a number of individual difference variables: left-toright political orientation (studies 1-4); social dominance orientation (Ho et al., 2015; study 1 only); and social trust (studies 2-4). These measures are not considered further in the present paper.

\section{Data analysis}

Data were analysed in $\mathrm{R}$ ( $\mathrm{R}$ Core Development Team, 2020), using linear mixed models, with random effects of participant to account for repeated measures. Significance testing (two-sided, $\alpha=0.05$ ) was based on Satterthwaite's method in R package 'ImerTest' (Kuznetsova et al., 2017). Inferences concerning the effect of a specific feature were based on the subset of the data (two villages) relevant to that feature. Model-based mediation analyses were performed with $\mathrm{R}$ package 'mediation' (Tingley et al., 2014). Where relevant, we decomposed effects of continuous predictors into their within-participant and between-participant components (van de Pol \& Wright, 2009). Our pre-registered predictions were as shown in table 2. Relevant statistical output is also shown in the table, so we do not repeat it in the Results narrative. Parenthetical P-numbers refer to the corresponding prediction and row in the table. Statistics for exploratory analyses are reported in the text.

\section{Results}

Ideal and Achievable Redistribution 
On average, achievable redistribution fell short of ideal redistribution in all conditions (average gap between ideal and achievable 7.94 points, se 0.86 ). This was not true of every single response, however: in almost $20 \%$ of individual responses, the achievable redistribution was higher than the ideal. The size of the average gap varied markedly across villages (smallest to largest: homogeneity 2.01; abundance 2.67; peace 3.75; effort 6.28; heterogeneity 8.94 ; luck 10.58; scarcity 14.39 ; war 14.92). 
Table 2. Pre-registered predictions and corresponding results for study 1.

\begin{tabular}{|c|c|c|c|c|}
\hline No. & Prediction & Confirmed? & Test & Marginal means (se) \\
\hline \multicolumn{5}{|c|}{ Redistribution (general) } \\
\hline P1. & $\begin{array}{l}\text { Features affect the two } \\
\text { types of redistribution } \\
\text { (ideal and actual) } \\
\text { differently }\end{array}$ & Yes & $F(1,4500)=50.46, p<0.001$ & \\
\hline \multicolumn{5}{|c|}{ Ideal redistribution } \\
\hline P2. & $\begin{array}{l}\text { Luck (versus effort) will } \\
\text { lead to higher ideal } \\
\text { redistribution. }\end{array}$ & Yes & $F(1,300)=31.48, p<0.001$ & $\begin{array}{l}\text { Luck: } 48.50 \text { (1.48) } \\
\text { Effort: } 39.44(1.48)\end{array}$ \\
\hline P3. & $\begin{array}{l}\text { Heterogeneity (versus } \\
\text { homogeneity) will lead to } \\
\text { lower ideal redistribution. }\end{array}$ & Yes & $F(1,300)=30.87, p<0.001$ & $\begin{array}{l}\text { Het: } 49.28(1.36) \\
\text { Hom.: } 42.22(1.36)\end{array}$ \\
\hline P4. & $\begin{array}{l}\text { War (versus peace) will } \\
\text { lead to higher ideal } \\
\text { redistribution. }\end{array}$ & No (null) & $F(1,300)=0.12, p=0.73$ & $\begin{array}{l}\text { War: } 46.72(1.82) \\
\text { Peace: } 47.60(1.82)\end{array}$ \\
\hline P5. & $\begin{array}{l}\text { Scarcity (versus } \\
\text { abundance) will lead to } \\
\text { lower ideal redistribution }\end{array}$ & $\begin{array}{l}\text { No (opposite } \\
\text { effect) }\end{array}$ & $F(1,300)=6.51, p=0.01$ & $\begin{array}{l}\text { Scarcity: } 51.99 \text { (1.49) } \\
\text { Abund.: } 47.60 \text { (1.49) }\end{array}$ \\
\hline \multicolumn{5}{|c|}{ Achievable redistribution } \\
\hline P6. & $\begin{array}{l}\text { Heterogeneity will lead to } \\
\text { lower achievable } \\
\text { redistribution }\end{array}$ & Yes & $F(1,300)=92.19, p<0.001$ & $\begin{array}{l}\text { Het: } 33.27(1.37) \\
\text { Hom.: } 47.27 \text { (1.37) }\end{array}$ \\
\hline P7. & $\begin{array}{l}\text { War will lead to lower } \\
\text { achievable redistribution. }\end{array}$ & Yes & $F(1,300)=33.43, p<0.001$ & $\begin{array}{l}\text { War: } 31.81(1.60) \\
\text { Peace: } 43.85(1.60)\end{array}$ \\
\hline P8. & $\begin{array}{l}\text { Scarcity will lead to lower } \\
\text { achievable } \\
\text { redistribution. }\end{array}$ & Yes & $F(1,300)=16.04, p<0.001$ & $\begin{array}{l}\text { Scarcity: } 37.59 \text { (1.46) } \\
\text { Abund.: } 44.93 \text { (1.46) }\end{array}$ \\
\hline \multicolumn{5}{|c|}{ Expected moral behaviour } \\
\hline P9. & $\begin{array}{l}\text { Different features affect } \\
\text { expected moral } \\
\text { behaviour differently }\end{array}$ & Yes & $F(3,2100)=85.24, p<0.001$ & \\
\hline P10. & $\begin{array}{l}\text { Heterogeneity will lead to } \\
\text { lower expected moral } \\
\text { behaviour. }\end{array}$ & Yes & $F(1,300)=278.04, p<0.001$ & $\begin{array}{l}\text { Het.: } 45.05 \text { (1.06) } \\
\text { Hom.: } 68.43(1.06)\end{array}$ \\
\hline P11. & $\begin{array}{l}\text { War will lead to lower } \\
\text { expected moral } \\
\text { behaviour. }\end{array}$ & Yes & $F(1,300)=281.15, p<0.001$ & $\begin{array}{l}\text { War: } 39.40(1.14) \\
\text { Peace: } 66.52(1.14)\end{array}$ \\
\hline P12. & $\begin{array}{l}\text { Scarcity will lead to lower } \\
\text { expected moral } \\
\text { behaviour. }\end{array}$ & Yes & $F(1,300)=185.17, p<0.001$ & $\begin{array}{l}\text { Scarcity: } 46.33(1.13) \\
\text { Abund.: } 67.13 \text { (1.13) }\end{array}$ \\
\hline P13. & $\begin{array}{l}\text { Expected moral } \\
\text { behaviour will be } \\
\text { positively associated with } \\
\text { achievable redistribution. }\end{array}$ & Yes & $B=0.39$, se $0.02, p<0.001$ & \\
\hline P14. & $\begin{array}{l}\text { Expected moral } \\
\text { behaviour will mediate } \\
\text { effects of situations on } \\
\text { achievable redistribution }\end{array}$ & Yes & $\begin{array}{l}\text { ACME } \\
\text { Het: } 6.76 \text {, se } 0.47, p<0.001 \\
\text { Sca.: } 6.77 \text {, se } 0.51, p<0.001 \\
\text { War: } 6.73 \text {, se } 0.43, p<0.001\end{array}$ & $\begin{array}{l}\text { \% effect mediated: } \\
\text { Het.: } 95 \% \\
\text { Scarcity } 96 \% \\
\text { War } 94 \%\end{array}$ \\
\hline
\end{tabular}




\begin{tabular}{|c|c|c|c|c|}
\hline \multicolumn{5}{|c|}{ Authoritarian governance preference } \\
\hline P15. & $\begin{array}{l}\text { Heterogeneity will lead to } \\
\text { higher authoritarian } \\
\text { governance } \\
\text { preference. }\end{array}$ & No (null) & $F(1,300)=2.22, p=0.13$ & $\begin{array}{l}\text { Het: } 48.88(0.75) \\
\text { Hom.: } 47.82(0.75)\end{array}$ \\
\hline P16. & $\begin{array}{l}\text { War will lead to higher } \\
\text { authoritarian governance } \\
\text { preference. }\end{array}$ & Yes & $F(1,300)=48.93, p<0.001$ & $\begin{array}{l}\text { War: } 53.24(0.85) \\
\text { Peace: } 46.65(0.85)\end{array}$ \\
\hline P17. & $\begin{array}{l}\text { Scarcity will lead to } \\
\text { higher authoritarian } \\
\text { governance preference. }\end{array}$ & Yes & $F(1,300)=202.36, p<0.001$ & $\begin{array}{l}\text { Scarcity: } 58.42(0.83) \\
\text { Abund.: } 46.37(0.83)\end{array}$ \\
\hline P18. & $\begin{array}{l}\text { Expected moral } \\
\text { behaviour of villagers will } \\
\text { be inversely related to } \\
\text { authoritarian } \\
\text { governance preference. }\end{array}$ & Yes & $B=-0.11$, se $0.01, p<0.001$ & \\
\hline
\end{tabular}

Het.: Heterogeneity; Hom.: Homogeneity; Abund.: Abundance; ACME: Average Causal Mediation Effect

Figure 1 visualizes the experimental effects on all dependent measures. As predicted, ideal redistribution was higher for luck than effort (P2), and lower for the heterogeneous than the homogeneous village (P3). Contrary to predictions, there was no significant effect of war on ideal redistribution (P4); and scarcity increased rather than decreasing it (P5).

As predicted, the situational features affected achievable redistribution differently from ideal redistribution ( $P 1)$. Achievable redistribution was higher where for luck than effort $(F(1,300)=9.89$, $p=0.002$ ), though the effect was smaller than for ideal redistribution (4.75 scale points versus 9.06 ). Heterogeneity reduced achievable redistribution, by a larger amount than its effect on ideal redistribution (P6; -14.00 scale points versus -7.06$)$. Both war (P7) and scarcity (P8) significantly reduced achievable redistribution. These effects contrast to those on ideal redistribution, which were null for war and in the opposite direction for scarcity. 


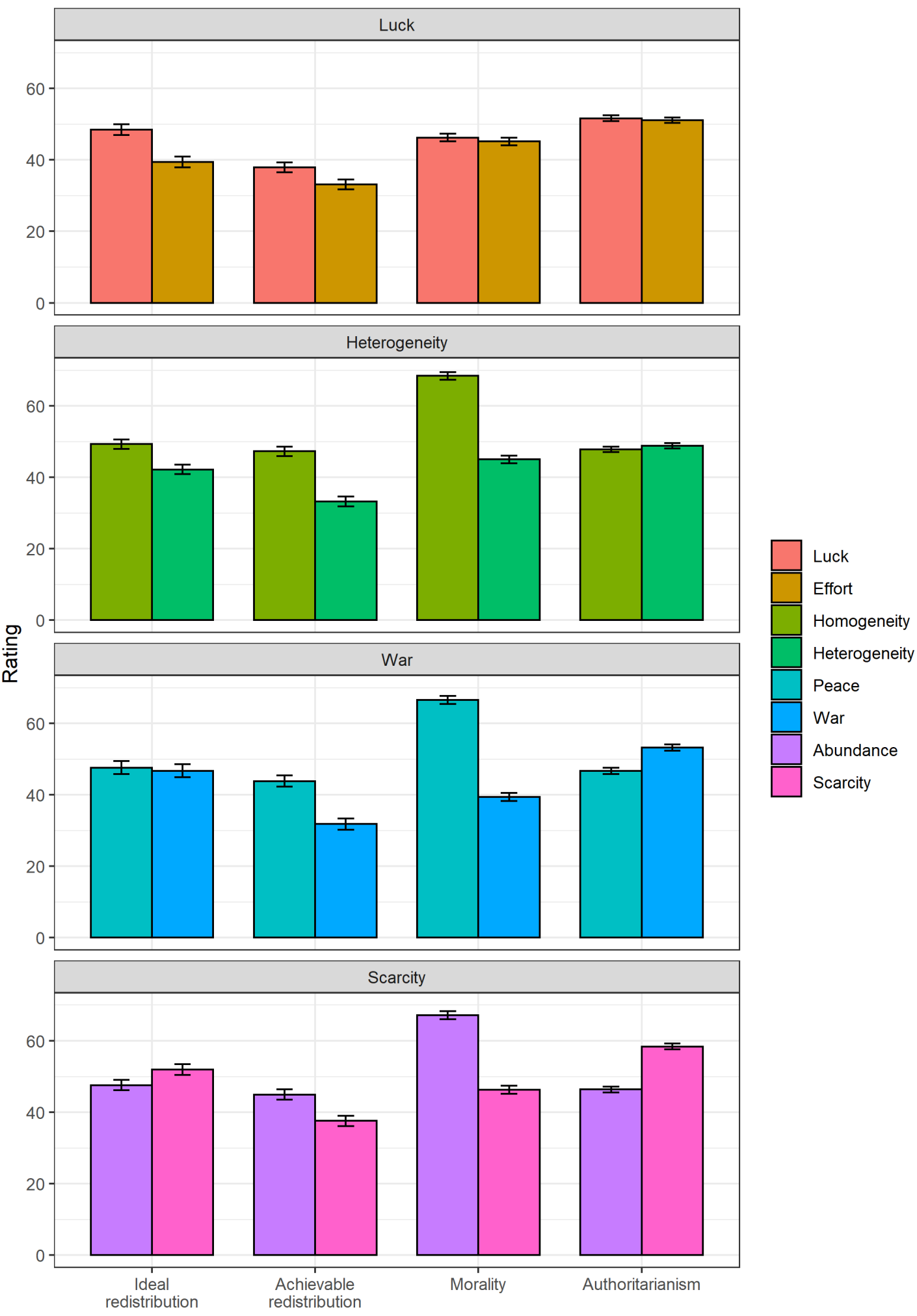

Figure 2. Summary of experimental effects, study 1. Each panel shows one situational feature, and each pair of bars represents on dependent measure. Bars show the estimated marginal means \pm 1 standard error for that dependent measure for the two levels of that situational feature. Morality: expected moral behaviour; Authoritarianism: authoritarian governance preference. 


\section{Expected moral behaviour}

Situational features affected expected moral behaviour, but to differing degrees (P9). We made directional predictions for effects on expected moral behaviour only for heterogeneity, war and scarcity. All three of these factors substantially reduced expected moral behaviour, with shifts of more than 10 scale points (P10-P12). We can take the high and low luck villages as a baseline for comparison, since there was no significant effect of luck on expected moral behaviour. Viewed in this way, it was not so much that heterogeneity, war and scarcity reduced expected moral behaviour but rather than homogeneity, peace, and abundance increased it relative to general expectation.

Expected moral behaviour positively predicted achievable redistribution; that is, greater redistribution was achievable where villagers would behave more morally (P13). We decomposed this association into the between-participants component (participants whose average expected moral behaviour was higher giving higher average achievable redistributions), and the withinparticipants component (participants shifting their achievable redistribution higher in those villages where they also shifted their expected moral behaviour higher). Both effects were significant, but the within-participant effect was stronger (between: $B=0.20$, se $0.09, p=0.04$; within: $B=0.40$, se $0.02, p<0.001)$. We predicted that expected moral behaviour would mediate the effects of heterogeneity, war and scarcity on achievable redistribution, and this was true in each case (P14). The percentage of the effect mediated was over $90 \%$ in all three cases. Expected moral behaviour also predicted ideal redistribution, but much more weakly than it predicted achievable redistribution ( $B=0.13$, se 0.02, $p<0.001$, compared to $B=0.39$, se $0.02, p<0.001$ ).

\section{Authoritarian governance preference}

We predicted effects on authoritarian governance preference for heterogeneity, war and scarcity. Contrary to prediction, the effect of heterogeneity on authoritarian governance preference was not significant (P15). As predicted, war (P16) and scarcity (P17) increased authoritarian governance preference. We expected authoritarian governance preference to vary inversely with expected moral behaviour, and this was indeed the case (P18). Decomposing this, there was both a betweenparticipants association (people with lower expected morality across villages have higher preference for authoritarian governance across villages; $B=-0.13$, se $0.06, p=0.02$ ) and a within-participants association (as people shift their expected morality lower for a given village, they shift their authoritarian governance preference higher; $\mathrm{B}=-0.11$, se $0.01, \mathrm{p}<0.001$ ).

Since the authoritarian governance preference scale was designed to capture multiple facets of authoritarianism, and the Cronbach $\alpha$ was fairly low (0.62), we disaggregated it to establish which items responded most to situational features. Taking the war and scarcity subsets of the data, there were significant effects of feature value on all six items. Much the largest effect sizes were for item 1 ('The village should have strong, tough leaders'; 19.21 points) and item 4 ('Everyone in this village should be free to pursue his or her own lifestyle (R)'; 16.76 points). Item 1, but not item 4, also differed significantly between homogeneous and heterogeneous villages, even though the total scale score did not $(F(1,300)=08.89, p<0.001)$. Finally, item 1 had a much stronger association to expected moral behaviour than the overall scale did (standardized $\beta$ for comparison; -0.31 for item $1,-0.17$ for overall scale).

\section{Discussion}

Study 1 was both a replication of Nettle and Saxe's (2020) findings regarding the effects of situational features on ideal redistribution, and an initial study of the effects of those same features on expected moral behaviour, achievable redistribution, and authoritarian governance preference. 
For ideal redistribution, the results of Nettle and Saxe (2020) were partially replicated. As predicted, luck increased ideal redistribution, and heterogeneity reduced it. Contrary to the earlier findings, war did not significantly increase ideal redistribution, and scarcity increased rather than decreasing it. We note a difference between the two studies: here, at time of responding to the ideal redistribution question, the respondents already knew that achievable redistribution would be separately asked. In Nettle and Saxe (2020), there was no such second question. The scarcity result in that study may have resulted from participants conflating strong negative predictions (scarcity will make redistribution lower) from positive moral prescriptions (scarcity ought to make it higher). The response format here, that clearly separated these two judgements, may have clarified what is being asked in the ideal redistribution question. Separating the two questions also demonstrated that moral cognition and the intuitive theory of social motivation are indeed somewhat independent: the same independent variable (e.g. scarcity) can increase the level of redistribution that ought to happen, while decreasing the level which is expected to happen.

We also established several key findings related to the intuitive theory of social motivation. Expected moral behaviour was strongly influenced by situational features. Specifically, expected moral behaviour was much higher when the respondent was specifically cued that the people were homogeneous, that the village lived in peace, or that resources were abundant, than in all other villages. In these three cases, villagers were expected to be morally good enough for the social world they create to be almost the ideal one (i.e. achievable redistribution was almost as high as ideal redistribution). Outside these conditions, the anticipated gap between achievable and ideal redistribution was large. Thus, our findings go beyond the previous generalization that people are pessimistic about the moral behaviour of others (Klein \& Epley, 2016). Rather, the intuitive theory predicts selfishness and amorality to decrease when people are surrounded by their own kind, free from the trouble of war or the existential threat of starvation.

War and scarcity led participants to judge that a lower level of redistribution would be achievable in practice, whatever the ideal (for heterogeneity, the non-significant trend was in this direction). These effects were almost perfectly mediated by expected moral behaviour. That is: societies in adverse situations were expected to achieve lower redistribution exactly to the extent their citizens were expected to behave immorally under those circumstances. Although we pre-registered this mediation pathway, we note that, since achievable redistribution and expected moral behaviour were both dependent variables in this experiment, we cannot really order one as the outcome and the other as the mediator. However, it is sufficient for our purposes to note that societal features cause expected moral behaviour and achievable redistribution to change in almost perfect lock-step, which makes sense given that participants in this paradigm view redistributing as a moral matter (Nettle \& Saxe, 2020).

Scarcity and war also led respondents to favour more authoritarian governance for the villages (especially, a strong, tough leader). This result was expected given prior literature on societal threat and authoritarianism. We were surprised that there was no significant effect of heterogeneity on authoritarian governance preference. There was a large effect of heterogeneity on expected moral behaviour, and for scarcity and war, expected moral behaviour and authoritarian governance preference moved in lockstep. We note that heterogeneity did increase endorsement of the strong leader item considered in isolation. Possibly some of the other authoritarian governance items (for example, about preserving their traditional values, and about every villager being free to pursue their own lifestyle) took on a different meaning in the context of a village described as culturally diverse, making the overall measure was relatively unsuitable. 
In our remaining experiments (studies 3-5), we probe how situational features lead to worse moral behaviour, and why authoritarian governance is intuitively the right solution to this problem. We focus on war and scarcity since those are the features for which the situational effects were clearest in study 1. Before doing so, however, we turn to a real-world dataset to triangulate the conclusion of study 1 on which we plan to build: that war and scarcity reliably increase preference for authoritarian governance.

\section{Study 2}

The experimental approach developed in study 1 allows us to causally isolate specific cognitive principles, but necessarily involves abstract judgements on hypothetical societies in which the respondent has no personal stake. In studies 3-5, we will use variants on the hypothetical societies paradigm to probe the intuitions behind one of the main results of study 1: that war and scarcity, but apparently not heterogeneity, increase preference for authoritarian governance. Before doing so, however, it is important to establish that these patterns of hypothetical judgement are consistent with real-world political preferences. To do this, we used data from wave 6 of the World Values Survey (WVS), a multi-country representative survey study of population-representative samples from 52 countries (that we were able to use here), totalling over 65,000 respondents. Specifically, we seek evidence that greater authoritarianism is associated with higher perceived threat of war and greater scarcity of resources, but not increased heterogeneity, across countries.

It is already well established in correlational data that authoritarianism is associated with measures of external threat (see General Introduction). This has even been shown using WVS wave 6 data: Fog (2019) finds that markers of authoritarianism are positively related to indices of collective threat, by which Fog means war or its perceived likelihood. Thus, we claim no novelty for the general hypothesis or approach of study 2 . However, no previous study has specifically operationalized either authoritarianism or collective threat in ways that correspond closely to the design of our study 1. Our aim here is to do so. We therefore developed a single-number measure of authoritarian governance preference from WVS questions. In addition, we measured respondent's concern about war or violent strife, following Fog (2019). To measure scarcity and heterogeneity, we use measures at the country level that come from outside the WVS: the Historical Index of Ethnolinguistic Fractionalization (Drazanova, 2020), and GDP per capita (International Monetary Fund, 2021). Our variables are therefore somewhat diverse: war threat is an individual-level appraisal, whereas the heterogeneity and scarcity variables are country-level objective indicators. In principle, we would prefer to use all subjective appraisals, since these are the targets of our psychological claims, but in WVS there are no questions asking for individuals' appraisals of how heterogenous they see their society as being, or how scarce they feel society's resources to be. (There are questions on individual income, but our experimental manipulation in studies 1-4 is of the total resource in society, not any individual's share). Thus, we retain this mixed approach, noting the caveat. Also, there are no straightforward operationalizations of our other relevant outcome variables, achievable redistribution and expected moral behaviour, within WVS. Thus, our focus in study 2 is only on authoritarianism and its situational predictors, not the fuller set of claims about the intuitive theory of social motivation. Note also that our choice of variables is based on what we predicted for study

1 , namely that heterogeneity, war and scarcity would increase authoritarian governance preference. Our actual findings conformed to prediction only for war and scarcity; the effect of heterogeneity, at least on the overall measure of authoritarian governance preference, was null.

\section{Methods}

Dataset 
We used data from wave 6 of the WVS (Inglehart et al., 2014). These were survey responses collected between 2010 and 2014 from representative samples in 60 countries ( 52 with all the measures of interest here; $n$ per country $662-2,877$, total $n 65,076$ ). Surveyed countries included all major continents and world regions, and a full range of levels of economic development.

\section{Measures}

To measure authoritarian governance preference, we created an index (higher is more authoritarian) from items V127, V128, and V129 in the WVS codebook: respectively, how good would it be 'to have a strong leader who does not have to bother with parliament and elections'; 'having experts, not government, make decisions according to what they think is best for the country'; and 'having the army rule'. The single principal component we used as the index explained $53 \%$ of the variation in these items (KMO 0.61).

The war threat variable was inspired by Fog (2019)'s index of perceived collective threat. Respondents were asked their level of worry about a war, a civil war or a terrorist attack involving their country (V183, V184, V185; with responses on four levels). A single principal component explained $87 \%$ of the variation in the responses across these questions (KMO 0.76), and we use this principal component score as our war threat variable (scored so a higher value is higher perceived threat of war).

To measure heterogeneity, we used the Historical Index of Ethnic Fractionalization (Drazanova, 2020). This is a country-level measure that varies from 0 , where all citizens belong to one ethnic group, to 1 , where every citizen is in a different ethnic group (observed range here $0.018-0.856$ ). The dataset gives longitudinal indices for each country, as it was designed for studying changing fractionalization over time. Here, we use the 2010 value for each country, as this was the starting year of wave 6 of the WVS.

For resource scarcity, we used per capita GDP in 2010 in US dollars, from the International Monetary Fund's World Economic Outlook database (International Monetary Fund, 2021).

\section{Data analysis and predictions}

Our outcome variable was authoritarian governance preference, with the three additive predictors being ethnic fractionalization, war threat, and GDP. GDP was log transformed for analysis. All continuous variables were standardized prior to analysis. We used a multi-level model, incorporating a random intercepts for each country, and random slopes by country for the effect of war threat. Below, we present results both unadjusted, and with further controls for respondent age (V242), sex (V240), perceived social class (V238), and income bracket (V239). Study 2 was not pre-registered.

\section{Results}

Model output is shown in table 3. Greater war threat was associated with higher authoritarian governance preference; lower GDP per capita was associated with higher authoritarian governance preference; and the association between ethnic fractionalization and authoritarian governance preference was not significant. These associations were not altered by adjusting for individual-level control variables. Figure 2 visualizes the results by scatterplots of country-level average authoritarian governance preference against country-level average war threat, plus GDP and ethnic fractionalization. Note that for war threat, this visualization understates the association, since $72 \%$ of the variance in war threat and $85 \%$ of the variance in authoritarian governance preference resided within countries, and there was a significant within-country association (i.e. the more threated people in a country are the more authoritarian, $\beta=0.059(0.004), t=16.74, p<0.001)$ as 
well as a between-country one (i.e. countries where the average person is more threated also have an average person who is more authoritarian; $\beta=0.160(0.047), t=3.38, p=0.001$ ).

Table 3. Model output for prediction of authoritarian governance preference by war threat, GDP per capita and ethnic fractionalization, with and without adjustment for covariates, study 2 .

\begin{tabular}{|c|c|c|c|c|c|c|}
\hline & \multicolumn{3}{|c|}{ Unadjusted model } & \multicolumn{3}{|c|}{ Adjusted model } \\
\hline Variable & $\beta$ (se) & $\mathrm{t}$ & $p$ & $\beta$ (se) & $\mathrm{t}$ & $p$ \\
\hline War threat & $\begin{array}{l}0.067 \\
(0.018)\end{array}$ & 3.73 & $<0.001$ & $0.069(0.018)$ & 3.81 & $<0.001$ \\
\hline $\log (G D P)$ & $\begin{array}{l}-0.111 \\
(0.050)\end{array}$ & -2.24 & 0.03 & $\begin{array}{l}-0.103 \\
(0.049)\end{array}$ & -2.08 & 0.04 \\
\hline $\begin{array}{l}\text { Ethnic } \\
\text { fractionalization }\end{array}$ & $\begin{array}{l}0.077 \\
(0.051) \\
\end{array}$ & 1.52 & 0.14 & $0.076(0.051)$ & 1.50 & 0.14 \\
\hline Age & & & & $\begin{array}{l}-0.023 \\
(0.039) \\
\end{array}$ & -6.03 & $<0.001$ \\
\hline Female & & & & $0.016(0.007)$ & 2.18 & 0.03 \\
\hline Social class & & & & $\begin{array}{l}-0.003 \\
(0.004) \\
\end{array}$ & -0.78 & 0.44 \\
\hline Income & & & & $0.020(0.004)$ & 4.52 & $<0.001$ \\
\hline
\end{tabular}
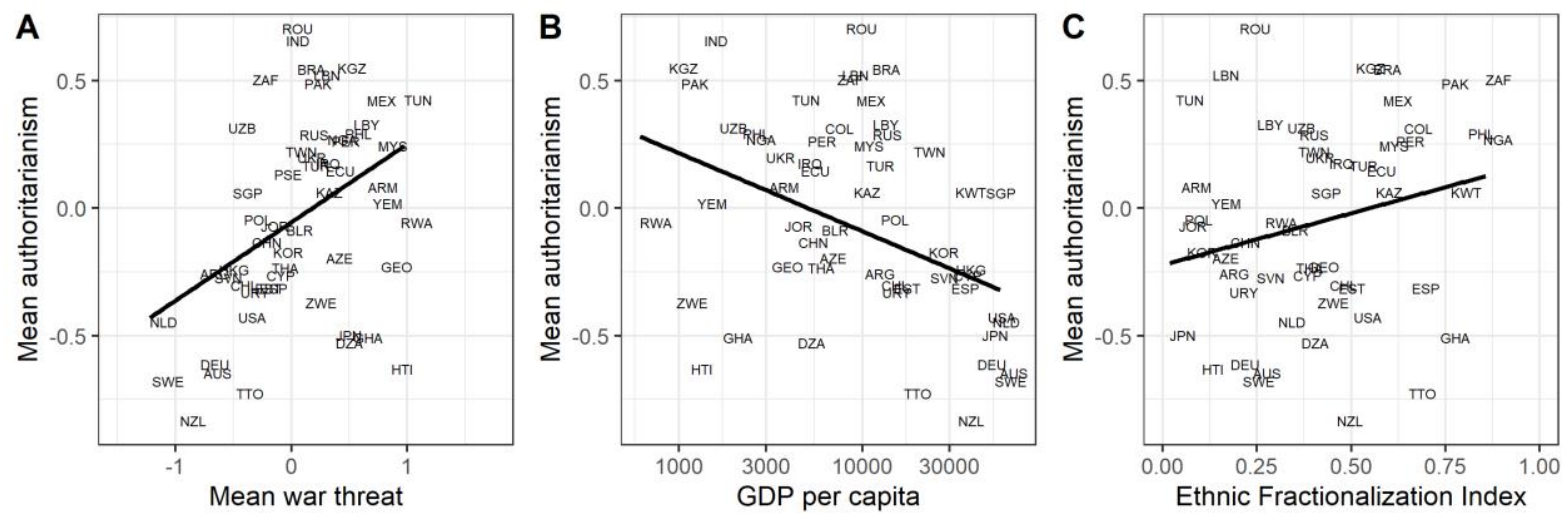

Figure 2. Country-level summaries of predictors of authoritarian governance preference, study 2. A. Mean authoritarian governance preference against mean war threat. B. Mean authoritarian governance preference against GDP per capita. C. Mean authoritarian governance preference against ethnic fractionalization. Symbols are ISO country codes.

\section{Discussion}

The results of study 2 suggest that a key conclusion of study 1 - that war and scarcity increase preference for authoritarian governance, though heterogeneity does not appear to - is consistent with what we observe in a large, real-world attitudinal dataset. This is especially pleasing since the study 1 results are based on within-subjects shifts in hypothetical judgments from a single participant pool, and those of study 2 on between- and within-country variation in judgements about their real country from representative samples of 52 nations. The findings of study 2 are consistent with those that have used large, cross-national surveys before (Fog, 2019; Jackson., 2019; Jackson et al., 2020). We present them here to establish the mapping between our experimental 
findings and a broader set of real-world data. Study 2 suffered from the limitation that only war threat was measured as the respondent's individual appraisal. Scarcity and heterogeneity were operationalized with country-level indicators. In fact, most of the variance to be explained in authoritarian governance preference is within countries; and no doubt inhabitants of the same country have divergent perceptions of heterogeneity and scarcity. A more sensitive test of the mapping to study 1 's findings would use individual-respondent perceived heterogeneity, and perceived scarcity of resources, instead of country-level proxies. The null association with heterogeneity in particular should be interpreted cautiously in this light. Set against this, the null association in study 2 accords with the findings of study 1 . Overall, the parallels between the withinsubjects effects in study 1 and the WVS patterns in study 2 suggest that the principles uncovered by our experimental approach are consequential for real-world attitudes. We this in mind, we return to the experimental studies.

\section{Study 3}

In study 1, participants held the intuitive theory that people behave worse (i.e. more selfishly and less morally) when there are societal threats such as war and scarcity than when there are not. In reality, we know the opposite can occur. If anything, war brings people in a society together, and increases their within-group altruism (Bauer et al., 2016; Bellows \& Miguel, 2009; Gneezy \& Fessler, 2012). Häusser et el. (2019) showed that participants intuitively expected hunger to reduce prosociality, but it did not in fact do so. Does this mean that the intuitive theory of social motivation simply makes inaccurate predictions? One possibility is that the function of the theory is not so much to make predictions that are accurate on average, but rather, to avoid extremely costly errors (Haselton \& Nettle, 2006). That is, war and scarcity may not be times when most others will actually behave badly. Rather, they may be times when it would be costly for there to be some others behaving badly and not to have noticed. Increased pessimism about the behaviour of others could be adaptive under circumstances that increase not the probability, but the costs, of other people's selfish behaviour; and hence the intuitive theory of social motivation generates greater vigilance for this possibility. We investigated this possibility in study 3.

We took just the war and scarcity pairs of villages, since these two features produced the largest effects on expected moral behaviour in study 1 . We deconstructed the expected moral behaviour to ask separately how many villagers will follow the rules concerning the common store in each circumstance, versus how bad a problem it is that a few villagers break the rules. In addition, we explored whether participants believe that any of the villagers would behave more morally in the more adverse situation.

Measures other than expected moral behaviour were the same as study 1 , but the presentation format was different. For each of war and scarcity, participants were presented with a village in the benign situation (i.e. peace or abundance). They were then asked to imagine, now, that a war or a famine breaks out, and asked what their views on the dependent measures now were. Thus, the design differs from study 1 in that the peace and war villages, for example, are specified to be the very same one, making the transition from one situational state to another, rather than different villages.

We predicted that scarcity and war will not lead to the expectation of all villagers behaving less morally; indeed, participants might expect some to behave better. Rather, we predicted the biggest impact of war and scarcity to be on ratings of how bad it would be for a few villagers to break the rules. Additionally, study 3 provides replication of scarcity and war on ideal and achievable redistribution, and on authoritarian governance preference, from study 1. 


\section{Methods}

Pre-registration

Design and predictions were pre-registered prior to data collection at https://osf.io/bnjfz.

Participants

Participants (73 men, 76 women, 1 self-described as unknown; mean age 35.85, sd 14.14) were recruited as for study 1 . We reduced the target sample size for study 2 from 300 to 150 . In study 1 , the effects of war and scarcity on each item of the expected moral behaviour scale were large (Cohen's $d: 0.55-0.82$ ). With 150 participants, power to detect an effect of $d=0.55$ at $\alpha=0.05$ is over $99 \%$, and the minimum detectable effect (or difference in effects) with $90 \%$ power is $d=0.27$.

\section{Design and materials}

The materials for study 3 were almost identical to the war and scarcity village-pairs of study 1 . For each pair, the low adversity village description was presented first, followed by the dependent measures. Then, a situational transition was described ('Now, a war breaks out with a neighbouring village.'/'Now, there is a famine and resources are scarce. There is only just enough for everyone's basic needs over all.'), and the dependent measures asked again. The order of presentation of the pairs was counterbalanced.

In place of the previous expected moral behaviour scale, we asked the following questions:

1. In this village, out of $\mathbf{1 0 0}$ villagers, about how many will strictly follow the rules concerning how much you must put in and how much you can take out of the common store?

2. In this village, how bad a problem would it be if even a few people don't strictly follow the common store rules? (slider 0-100, anchored with 'Not at all bad' and 'Extremely bad').

3. Of 100 villagers, about how many will behave more morally than in peacetime/in times of plenty? (give a number; war/scarcity case only)

4. Of 100 villagers, about how many will behave less morally than in peacetime/in times of plenty? (give a number; war/scarcity case only)

\section{Data analysis}

The general data analysis strategy was as for study 1 . The pre-registered predictions and corresponding statistical output are summarised in table 4.

\section{Results}

Figure 3 summarises the experimental effects. As predicted, scarcity substantially increased ideal redistribution $(P 1)$. This was also true for $\operatorname{war}(F(1,149)=10.77, p=0.001)$, though we had not predicted this due to the null effect in study 1 . Against our predictions $\mathrm{P} 2$ and $\mathrm{P} 3$, neither scarcity nor war had any significant effect on achievable redistribution. Participants believed the onset of war or scarcity should make redistribution go up, but would in practice fail to do so. As predicted, participants had higher authoritarian governance preferences when the villages faced war (P4) or scarcity (P5). All six scale items individually showed shifts, with the largest for 'The village should have strong, tough leaders' (20.57 points, averaged across the war and scarcity pairs), 'Villagers should be allowed to question and challenge decisions they do not like' (-18.50 points), and 'Everyone in this village should be free to pursue his or her own lifestyle' (-17.38 points).

Participants believed the number of villagers out of 100 who would strictly follow the rules would reduce in war $(F(1,148.71)=35.05, p<0.001)$ and scarcity $F(1,148.9)=52.50, p<0.001)$. However, 
the proportion expected to comply was still over half on average (peace, 69.98, war 57.97, abundance 69.93 , scarcity 52.33). Participants believed that some villagers would behave more morally under war or scarcity, and also some villagers less morally (more morally in wartime: mean 44.21, sd 30.83; less morally in wartime: mean 41.61, sd 28.43; more morally in scarcity: mean 46.35, sd 31.33; less morally in scarcity: mean 43.67, sd 27.84). Few participants believed that war or scarcity would make no villager more moral (15 and 14 participants respectively). On the other hand, very few believed that war or scarcity would make no villager less moral ( 5 and 6 participants respectively).

We asked how bad a problem it would be if even a few villagers didn't strictly follow the common store rules. Ratings here were much higher for war than peace $(F(1,148.1)=116.64, p<0.001)$, and scarcity than abundance $(F(1,149.18)=29.7 .95, p<0.001)$. We predicted $(P 6)$ that adversity would more strongly affect how bad it would be for a few villagers to break the rules, than the number expected to do so. To test this prediction, we compared the standardized effect size of adversity on each measure, averaging across the war and scarcity pairs. The effect size was indeed around twice as large for how bad compared to number compliant. 
Table 4. Pre-registered predictions and corresponding results for study 3.

\begin{tabular}{|c|c|c|c|c|}
\hline No. & Prediction & Confirmed? & Test & Marginal means (se) \\
\hline \multicolumn{5}{|c|}{ Ideal redistribution } \\
\hline P1. & $\begin{array}{l}\text { Ideal redistribution will } \\
\text { be higher for the scarcity } \\
\text { village than the } \\
\text { abundance village. }\end{array}$ & Yes & $F(1,149)=25.05, p<0.001$ & $\begin{array}{l}\text { War: } 59.50(2.46) \\
\text { Peace: } 44.40(2.46)\end{array}$ \\
\hline \multicolumn{5}{|c|}{ Achievable redistribution } \\
\hline P2. & $\begin{array}{l}\text { Achievable redistribution } \\
\text { will be lower for the war } \\
\text { village than the peace } \\
\text { village. }\end{array}$ & No (null) & $F(1,149)=0.53, p=0.47$ & $\begin{array}{l}\text { War: } 39.24(2.13) \\
\text { Peace: } 37.81(2.13)\end{array}$ \\
\hline P3. & $\begin{array}{l}\text { Achievable redistribution } \\
\text { will be lower for the } \\
\text { scarcity village than the } \\
\text { abundance village. }\end{array}$ & No (null) & $F(1,149)=0.22, p=0.64$ & $\begin{array}{l}\text { Scarcity: } 37.30(2.26) \\
\text { Abundance: } 38.44(2.26)\end{array}$ \\
\hline \multicolumn{5}{|c|}{ Authoritarian governance preference } \\
\hline P4. & $\begin{array}{l}\text { Authoritarian governance } \\
\text { preference will be higher } \\
\text { for the war village than } \\
\text { the peace village. }\end{array}$ & Yes & $\begin{array}{l}F(1,146.91)=101.82, p< \\
0.001\end{array}$ & $\begin{array}{l}\text { War: } 56.47 \text { (1.17) } \\
\text { Peace: } 45.55 \text { (1.17) }\end{array}$ \\
\hline P5. & $\begin{array}{l}\text { Authoritarian governance } \\
\text { preference will be higher } \\
\text { for the scarcity village } \\
\text { than the abundance } \\
\text { village. }\end{array}$ & Yes & $\begin{array}{l}F(1,146.91)=95.91, p< \\
0.001\end{array}$ & $\begin{array}{l}\text { Scarcity: } 43.62 \text { (1.23) } \\
\text { Abundance: } 56.30 \text { (1.23) }\end{array}$ \\
\hline \multicolumn{5}{|c|}{ Novel expected morality questions } \\
\hline P6. & $\begin{array}{l}\text { Scarcity and war will } \\
\text { more strongly increase } \\
\text { how bad it would be for } \\
\text { even a few people to } \\
\text { break the rules, than the } \\
\text { number of people } \\
\text { expected to break the } \\
\text { rules. }\end{array}$ & Yes & \multicolumn{2}{|c|}{$\begin{array}{l}\text { Standardized effect sizes (se): } \\
\text { Scarcity: } \\
\text { How bad: } 0.85(0.08) \\
\text { Number: }-0.45(0.08) \\
\text { War: } \\
\text { How bad: } 1.41(0.08) \\
\text { Number: }-0.61(0.08)\end{array}$} \\
\hline
\end{tabular}




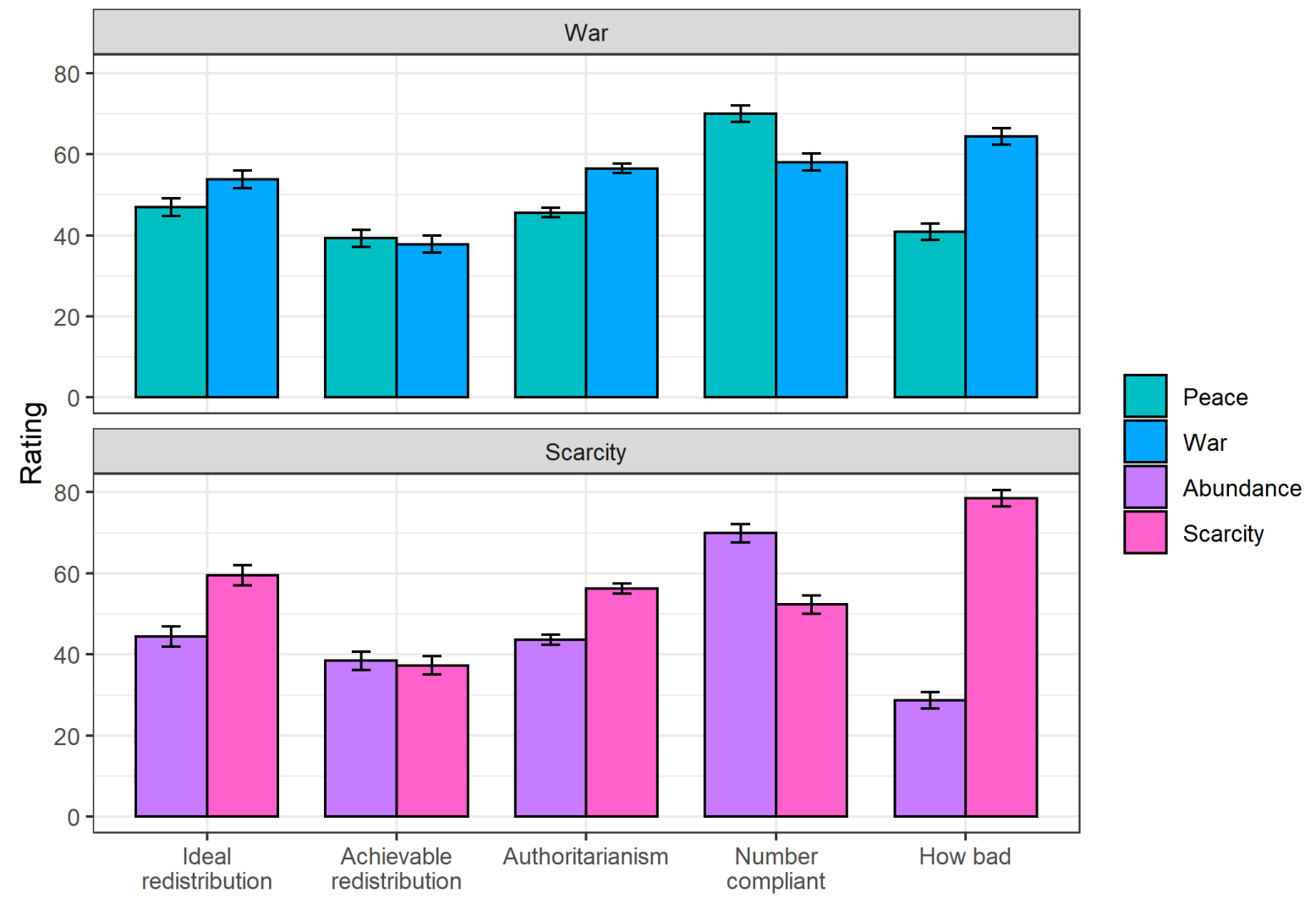

Figure 3. Summary of experimental effects, study 3. Each panel shows one situational feature, and each pair of bars represents on dependent measure. Bars show the estimated marginal means \pm 1 standard error for that dependent measure for the two levels of that situational feature. Number compliant: Number of villagers out of 100 who will comply with the common-store rules; How bad: How much of a problem it would be if even a few villagers did not comply with the common-store rules.

\section{Discussion}

The main objective of study 3 was to establish whether participants believe that societal adversity such as war and scarcity would make everyone behave worse; would make some people behave worse and some better; or would simply make it more of a problem that the existing number of wrongdoers persisted. We found support for the hypothesis that any given level of cheating is seen as more deleterious under adversity than normal times: the largest effect size was that of scarcity or war on how bad a problem it would be if even a few villagers failed to comply with the commonstore rules. It seems our participants were able to consider the amount of slack or buffer that the situation allows for: a certain level of immorality can be absorbed under benign conditions, but not when things are desperate.

Nonetheless, we did also find that participants expected the proportion of villagers complying with the common store rules to go down in adverse situations. The vast majority of participants believed that some villagers would behave more morally under adversity, as well as some behaving less morally. The fraction expected to behave more morally was on average slightly larger than that expected to behave less morally. Thus, there is no contradiction between the intuitive response seen in study 1 , that adverse situations are expected to make people behave worse, and the widespread observation that societal adversity makes people prosocial, especially toward their in-group (Bauer 
et al., 2016; Bellows \& Miguel, 2009; Gneezy \& Fessler, 2012). Participants intuitively expect both things to happen. In bad situations, though, the former is perceived as a serious problem, making people vigilant for it.

We replicated the finding of study 1 that scarcity and war differentially affect ideal and achievable redistribution. The effects were not exactly the same in the two studies, however. In study 1 , scarcity and war made rather little difference to the ideal level of redistribution, but had large negative effects on what would be achievable in practice. Here, scarcity and war increased the ideal level of redistribution substantially, whereas the achievable level stayed much the same. Note that the two tasks are somewhat different. In study 1, participants were assessing ideal and achievable levels for different villages under different conditions. Here, they were assessing what ought to change when the same village faces a sudden transition to war or famine. Their response here (that the village ought to increase its redistribution in response, but would not manage to in practice given social motivation) still reflects the same basic fact that adversity increases the size of the gap between what ought to happen and what actually does, because (at least some) members of society behave badly.

We also replicated the findings from studies 1 and 2 that scarcity and war increase authoritarian governance preference - here in terms of a preference for change to greater authoritarianism within the same village as the situation becomes more threatening. The effect sizes were comparable to study 1. Again, the item within the authoritarianism scale that showed the greatest response was 'the village should have strong, tough leaders'.

Study 3 had a limitation in that, due to the design, abundance always preceded scarcity, and peace always preceded war. This would limit inferences about the intuited effects of the specific situation compared to, say, the effects of any social change. However, study 1 counterbalanced the order of scarcity and abundance, and peace and war. As noted above, the directly comparable experimental effect (that on authoritarian governance preference) was very similar in size and direction. Thus, we feel confident interpreting the experimental effects as reflecting intuitions about the effects of scarcity and abundance.

\section{Study 4}

Studies 1 and 3 showed that people want strong, authoritarian leaders when immorality is expected because the societal situation is threatening. Study 4 investigated why. If preference for strong leaders is found where expected moral behaviour is low, this implies that people believe strong leaders can reverse or at least mitigate immoral behaviour. However, we have not yet tested this directly. We examined a village expected to generate high levels of moral behaviour and achievable redistribution (a village with abundance), and one expected to generate the opposite (a village under scarcity). Each village was presented first without, and then with, a strong, tough leader who insists on obedience and does not tolerate dissent. We choose to focus on the scarcity case, as for war, the preference for a strong leader may be related to intuitions about fighting ability; for scarcity that seems unlikely to be the driving consideration.

First, as further replication of studies 1-3, we sought to confirm that the advent of the strong leader was viewed as a better thing for the scarcity village than the abundance village. We then sought to adjudicate between several possible hypotheses for why. The first possibility (differential effectiveness) is that the strong leader is viewed as effective at increasing morality and achievable redistribution only (or more strongly) under scarcity, explaining why such a leader is more favoured 
under these conditions. The second possibility (uniform effectiveness) is that the strong leader is viewed as equally effective at increasing morality and achievable redistribution in both situations, but people may believe that it is not worth paying the costs, or there are better alternative means of achieving the same effect, in abundance. The third possibility (no effectiveness) is that the strong leader has no effect on morality or achievable redistribution, in which case the stronger preference for such a leader under scarcity is due to some other reason (such as, for example, that the strong leader is individually better at surviving the scarcity).

We asked additional exploratory questions about how strong leaders might increase moral behaviour and achievable redistribution: this could be via specific deterrence (people who were formerly breaking the rules will now desist), general deterrence (people who were not formerly breaking the rules but might have been tempted to start will not now do so), or by encouraging greater positive productive efforts amongst those who were already abiding by the rules.

\section{Methods}

Pre-registration

Predictions for confirmatory analysis, and intended exploratory analyses, were pre-registered at https://osf.io/6t53e.

\section{Participants}

One hundred and fifty participants ( 75 men, 75 women, mean age 36.97 years, s.d. 12.92 ) were recruited as for study 1 . In study 1 , the effect of scarcity on preference for a strong leader (item 1 of the authoritarianism scale) was fairly large $(d=0.52)$. With 150 participants, power to detect an effect of $d=0.52$ at $\alpha=0.05$ is over $99 \%$. The minimum detectable effect (or difference in effects) with $90 \%$ power is $d=0.27$.

\section{Design and materials}

The materials were based on the scarcity pair of villages from study 1 , presented in random order. We first presented each village using the standard description, and measured ideal and achievable redistribution and expected moral behaviour $(\alpha=0.82)$ as before. We then specified that the village has a strong, tough leader. The leader insists on obedience. Villagers are not allowed to question or challenge decisions they do not like, before measuring ideal and achievable redistribution, and expected moral behaviour, a second time. In addition, we asked how good it was for the village that the strong leader came along; and for agreement with three statements: that individuals who had previously cheated on the common-store rules would now follow them; that individuals who might have been tempted to start cheating would not now do so; and that rule-abiding individuals would now give even more to the store, and take out even less.

\section{Data analysis and predictions}

The general data analysis strategy was as for study 1 . Interactions between scarcity and leader were always included in models but were non-significant unless otherwise stated. Pre-registered predictions and corresponding results are shown in table 5 .

\section{Results}

Figure 4 shows the main experimental results. Ideal redistribution was significantly higher under scarcity than abundance (P1). It was also significantly higher under the strong leader than baseline, contrary to our null prediction (P8). We predicted the scarcity would reduce achievable 
redistribution, but the effect was null (P2). Strong leaders did however increase achievable redistribution, equally for scarcity and abundance villages (P6).

Table 5. Pre-registered predictions and corresponding results for study 4.

\begin{tabular}{|c|c|c|c|c|}
\hline No. & Prediction & Confirmed? & Test & Marginal means (se) \\
\hline \multicolumn{5}{|c|}{ Ideal redistribution } \\
\hline P1. & $\begin{array}{l}\text { Ideal redistribution will } \\
\text { be higher under scarcity } \\
\text { than abundance. }\end{array}$ & Yes & $F(1,447)=5.32, p=0.02$ & $\begin{array}{l}\text { Scarcity: } 52.73(2.07) \\
\text { Abundance: } 48.76 \\
(2.07)\end{array}$ \\
\hline \multicolumn{5}{|c|}{ Achievable redistribution } \\
\hline P2. & $\begin{array}{l}\text { Without the strong leader } \\
\text { treatment, achievable } \\
\text { redistribution will be } \\
\text { lower under scarcity than } \\
\text { abundance. }\end{array}$ & No (null) & $F(1,149)=1.01, p=0.32$ & $\begin{array}{l}\text { Scarcity: } 37.50(2.10) \\
\text { Abundance: } 39.98 \\
(2.10)\end{array}$ \\
\hline \multicolumn{5}{|c|}{ Expected moral behaviour } \\
\hline P3. & $\begin{array}{l}\text { Without the strong leader } \\
\text { treatment, expected } \\
\text { moral behaviour will be } \\
\text { lower under scarcity than } \\
\text { abundance. }\end{array}$ & Yes & $F(1,149)=56.70, p<0.001$ & $\begin{array}{l}\text { Scarcity: } 47.33(1.66) \\
\text { Abundance: } 64.79 \\
(1.66)\end{array}$ \\
\hline \multicolumn{5}{|c|}{ Strong leader treatment } \\
\hline P4. & $\begin{array}{l}\text { The strong leader will be } \\
\text { rated a better thing under } \\
\text { scarcity than abundance. }\end{array}$ & Yes & $\begin{array}{l}F(1,147.86)=21.92, p< \\
0.001\end{array}$ & $\begin{array}{l}\text { Scarcity: } 61.70(2.10) \\
\text { Abundance: } 51.47 \\
(2.10)\end{array}$ \\
\hline P5. & $\begin{array}{l}\text { The strong leader } \\
\text { treatment will increase } \\
\text { expected moral } \\
\text { behaviour. }\end{array}$ & $\begin{array}{l}\text { Yes, but only } \\
\text { for scarcity } \\
\text { village }\end{array}$ & $\begin{array}{l}\text { Interaction with scarcity: } \\
F(1,447)=10.45, p<0.001\end{array}$ & $\begin{array}{l}\text { Scarcity baseline: } 47.33 \\
(1.60) \\
\text { Scarcity strong: } 55.75 \\
(1.60) \\
\text { Abundance baseline: } \\
64.79 \text { (1.60) } \\
\text { Abundance strong: } \\
64.44(1.60)\end{array}$ \\
\hline P6. & $\begin{array}{l}\text { The strong leader } \\
\text { treatment will increase } \\
\text { achievable redistribution. }\end{array}$ & Yes & $F(1,447)=49.94, p<0.001$ & $\begin{array}{l}\text { Baseline: } 38.74(1.80) \\
\text { Strong: } 50.28(1.80)\end{array}$ \\
\hline P7. & $\begin{array}{l}\text { Increased expected moral } \\
\text { behaviour will mediate } \\
\text { the effect of the strong } \\
\text { leader treatment on } \\
\text { achievable redistribution. }\end{array}$ & Yes & $\begin{array}{l}\text { ACME } 1.29, \text { se } 0.48, p< \\
0.001\end{array}$ & $\begin{array}{l}\text { Percentage effect } \\
\text { mediated: } \\
11 \% \text { overall } \\
32 \% \text { scarcity village } \\
\text { alone }\end{array}$ \\
\hline P8. & $\begin{array}{l}\text { The strong leader } \\
\text { treatment will have no } \\
\text { effect on ideal } \\
\text { redistribution. }\end{array}$ & $\begin{array}{l}\text { No, positive } \\
\text { effect }\end{array}$ & $F(1,447)=6.52, p=0.01$ & $\begin{array}{l}\text { Baseline: } 48.54(2.07) \\
\text { Strong: } 52.94(2.07)\end{array}$ \\
\hline
\end{tabular}

For expected moral behaviour, there was an interaction between scarcity and leader (whereas we had predicted a main effect, P5). Strong leaders did not affect expected moral behaviour under 
abundance, where it was already high, but increased it under scarcity. We predicted (P7) that the effect of strong leaders on achievable redistribution would be partially or wholly mediated by their effect on moral behaviour. There was a significant mediation effect (average causal mediation effect 1.29 , se $0.48, p<0.001)$. However, this only accounted for $11 \%$ of the association between strong leadership and achievable redistribution. This percentage rose to $32 \%$ considering conditions of scarcity alone.

The coming of the strong leader was seen as more desirable for the scarcity than the abundance village (P4). In terms of effects of a strong leader, the highest endorsement was for making those individuals who had previously been breaking the common-store rules stop (mean 64.01, sd 23.20). This was rated more highly than deterring those who might have been tempted to start breaking the rules from doing so (mean 57.98, $\mathrm{sd} 29.10, \mathrm{t}=-2.98, \mathrm{p}=0.003$ ), which in turn was rated more highly than increasing prosocial efforts from those who already abide by the rules (mean 44.78, sd 25.20, $\mathrm{t}$ $=-6.21, \mathrm{p}<0.001)$.

A

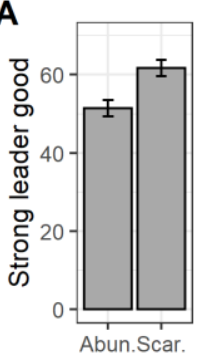

B

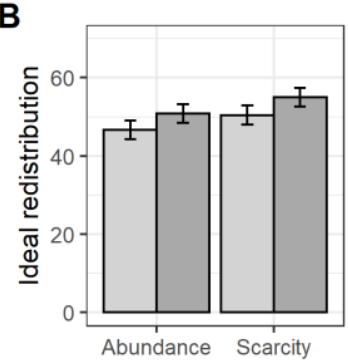

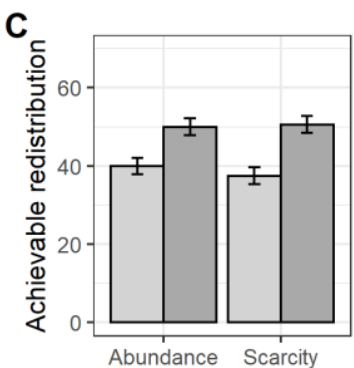

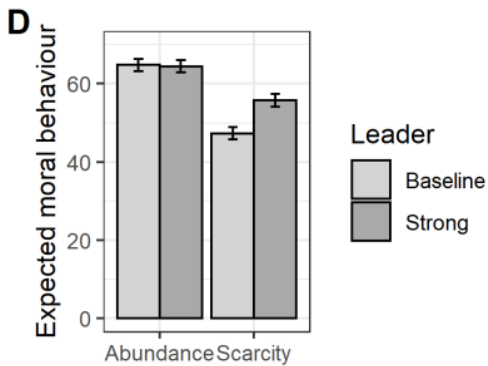

Figure 4. Main experimental results, study 4. A: rating of strong leader as a good thing, by scarcity; B: effects of scarcity and strong leader on ideal redistribution; C: effects of scarcity and strong leader on achievable redistribution; D: effects of scarcity and strong leader on expected moral behaviour. Plots show estimated marginal means \pm 1 standard error.

\section{Discussion}

Study 4 confirmed the findings of studies 1-3 that authoritarianism is preferred when society faces scarcity. In the baseline conditions, we replicated the pattern of study 3: people believe that when a society faces scarcity, redistribution ought to increase, but will not do so in practice, because morality and compliance will decline. A strong leader, however, can make a difference to this, increasing achievable redistribution and improving moral behaviour.

We again note the limitation that, within a village pair, the order of normal leader and strong leader was not counterbalanced. However, it is easier in terms of design to go from a condition where the participant has no information about the leader (our baseline) to one in which there is specific information about the leader (the strong leader treatment), than vice versa. This is why we did not randomise. The fact that comparable results triangulate well with studies 1 and 3 reassures us that we are capturing intuitions about strong leadership rather than just, for example, the consequences of having more information about the village.

In terms of the alternative possibilities laid out in the introduction to this study, the effects were somewhat incoherent, supporting differential effectiveness for expected moral behaviour, and uniform effectiveness for achievable redistribution. Strong leaders only had a positive effect on moral behaviour under scarcity, when moral behaviour was low anyway; under abundance, they made no difference at all. The preference for a strong leader in times of scarcity cannot be explained 
by strong leaders being differentially effective at increasing redistribution in such times: they were rated equally good at increasing it in times of abundance. Rather, they are more preferred when they are more effective at increasing the level of moral behaviour.

As for how strong leaders increase achievable redistribution, the strongest effect was on the behaviour of those currently breaking the rules. This was rated more highly than deterring those who were not currently breaking the rules from the temptation to start, and much more highly than inducing greater prosocial efforts from the rule-abiding. Taken alongside the findings of study 3 , these patterns suggest that participants' typical intuition about society under conditions of adversity is not that everyone will behave badly, but that a small sub-group will and this will be a big problem; that strong leaders are good at changing the behaviour of this sub-group in particular; and hence that they should be called for particularly in such situations.

One puzzling feature of study 4 is that strong leaders modestly increased ideal redistribution, when our specific prediction was that they would increase the achievable but not the ideal. The effect size was smaller than for achievable redistribution. Why this effect should occur is unclear. Possibly, the presence of the strong leader was causing participants to back-infer other, unspecified features of the society - greater homogeneity, for example - that were relevant to ideal redistribution.

\section{Study 5}

In study 4, we found that respondents thought a strong leader would be able to increase the moral behaviour of members of society specifically under conditions of scarcity, but not under conditions of abundance. This implies the respondents believed that people faced with scarcity do not just behave differently with respect to moral obligations, but respond differently to influences or interventions on their moral behaviour. Thus, we hypothesized that the means of influence available without authoritarian leaders, such as people's inherent desire to be moral, and rational persuasion, will be judged less effective under scarcity, whereas the means that require an authoritarian leader, notably harsh punishment, will be more effective under scarcity.

In study 5, we therefore followed up study 4 to investigate what will be effective in achieving compliance under scarcity versus abundance. Instead of asking respondents to set a level of redistribution, we fixed one, and asked respondents which of various influences would be most effective in making villagers comply. The hypothesis of the study was that the means available to authoritarian leaders (notably, punishment) would be more effective under scarcity, whereas those that do not require such an authority (e.g. rational argument) would be less effective. In direct replication of study 4, we also asked how good a thing it would be for each village to have an authoritarian strong leader.

\section{Methods}

Pre-registration

Design and predictions for confirmatory analysis were preregistered at https://osf.io/6h8tx.

\section{Participants}

One hundred and fifty participants ( 73 men, 77 women, 1 self-described as transmasculine; mean age 34.26, s.d. 13.18) were recruited as for study 1.

\section{Design and materials}


The scarcity and abundance villages of study 5 were presented in random order. For each one, we explained that the villages had set a redistribution rate of $50 \%$. We then asked how effective each of six influences, considered on its own, would be in making people comply with the rules: inherent motivation to do what is right; rational arguments for why the common store system is a good one; informal peer pressure; traditional village customs and rituals around the common store; a high likelihood of being caught for anyone breaking the rules; and harsh punishment for anyone who is caught breaking the rules. Finally, we asked participants to rate their level of agreement with the statement 'it would be a good thing for the village if a strong, tough leader came along'.

\section{Data analysis}

The general data analysis strategy was as for study 1 . Pre-registered predictions and corresponding results are shown in table 6 .

\section{Results}

Figure 5 shows the main experimental results. As predicted, under scarcity as compared to abundance, villagers' inherent motivation to do what is right (P1), and rational argument (P2), were rated significantly less effective in producing compliance. Against our predictions, there were no significant differences in effectiveness for informal peer pressure (P3) or traditional customs and rituals (P4). In accordance with prediction, high likelihood of punishment (P5), and harsh punishment for those caught (P6), were rated as more effective under scarcity than abundance.

As predicted, participants rated the emergence of a strong tough leader as a better thing for the scarcity village than the abundance village (P7). How good a strong leader would be depended on how effective harsh punishment would be $(B=0.24$, se $0.06, p<0.001)$. This association held significantly both at the between-subjects level (i.e. averaged across conditions, participants who thought punishment was more effective rated strong leaders higher, $B=0.17$, se $0.08, p=0.04$ ) and within subjects (i.e. the size of the within-person shift in rated punishment effectiveness predicted the size of the shift in rating of strong leader, $B=0.30$, se $0.08, p<0.001$ ). 
Table 6. Pre-registered predictions and corresponding results for study 5.

\begin{tabular}{|c|c|c|c|c|}
\hline No. & Prediction & Confirmed? & Test & Marginal means (se) \\
\hline P1. & $\begin{array}{l}\text { Inherent motivation to do } \\
\text { what is right will be rated } \\
\text { less effective under } \\
\text { scarcity than abundance. }\end{array}$ & Yes & $F(1,149)=7.79, p=0.006$ & $\begin{array}{l}\text { Scarcity: } 62.94 \text { (1.91) } \\
\text { Abundance: } 69.95 \\
(1.91)\end{array}$ \\
\hline P2. & $\begin{array}{l}\text { Rational arguments be } \\
\text { rated less effective under } \\
\text { scarcity than abundance. }\end{array}$ & Yes & $\begin{array}{l}F(1,149.52)=6.52, p= \\
0.01\end{array}$ & $\begin{array}{l}\text { Scarcity: } 63.83 \text { (1.76) } \\
\text { Abundance: } 69.01 \\
\text { (1.76) }\end{array}$ \\
\hline P3. & $\begin{array}{l}\text { Informal peer pressure } \\
\text { will be rated less effective } \\
\text { under scarcity than } \\
\text { abundance. }\end{array}$ & No & $\begin{array}{l}F(1,149.04)=0.02, p= \\
0.90\end{array}$ & $\begin{array}{l}\text { Scarcity: } 63.92 \text { (1.96) } \\
\text { Abundance: } 63.62 \\
(1.96)\end{array}$ \\
\hline P4. & $\begin{array}{l}\text { Traditional village } \\
\text { customs and rituals will } \\
\text { be less effective under } \\
\text { scarcity than abundance. }\end{array}$ & No & $F(1,148.4)=0.01, p=0.90$ & $\begin{array}{l}\text { Scarcity: } 69.49 \text { (1.70) } \\
\text { Abundance: } 69.74 \\
(1.69)\end{array}$ \\
\hline P5. & $\begin{array}{l}\text { A high likelihood of } \\
\text { punishment will be more } \\
\text { effective under scarcity } \\
\text { than abundance. }\end{array}$ & Yes & $\begin{array}{l}F(1,149.6)=23.91, p< \\
0.001\end{array}$ & $\begin{array}{l}\text { Scarcity: } 73.76(1.95) \\
\text { Abundance: } 62.00 \\
(1.95)\end{array}$ \\
\hline P6. & $\begin{array}{l}\text { Harsh punishment will be } \\
\text { more effective under } \\
\text { scarcity than abundance. }\end{array}$ & Yes & $\begin{array}{l}\mathrm{F}(1,147.94)=18.19, \mathrm{p}< \\
0.001\end{array}$ & $\begin{array}{l}\text { Scarcity: } 73.10(2.08) \\
\text { Abundance: } 63.58 \\
(2.06)\end{array}$ \\
\hline P7. & $\begin{array}{l}\text { The strong leader will be } \\
\text { rated a better thing for } \\
\text { the village under scarcity } \\
\text { than abundance. }\end{array}$ & Yes & $\begin{array}{l}F(1,147.13)=37.35, p< \\
0.001\end{array}$ & $\begin{array}{l}\text { Scarcity: } 58.34 \text { (2.05) } \\
\text { Abundance: } 45.67 \\
(2.06)\end{array}$ \\
\hline
\end{tabular}



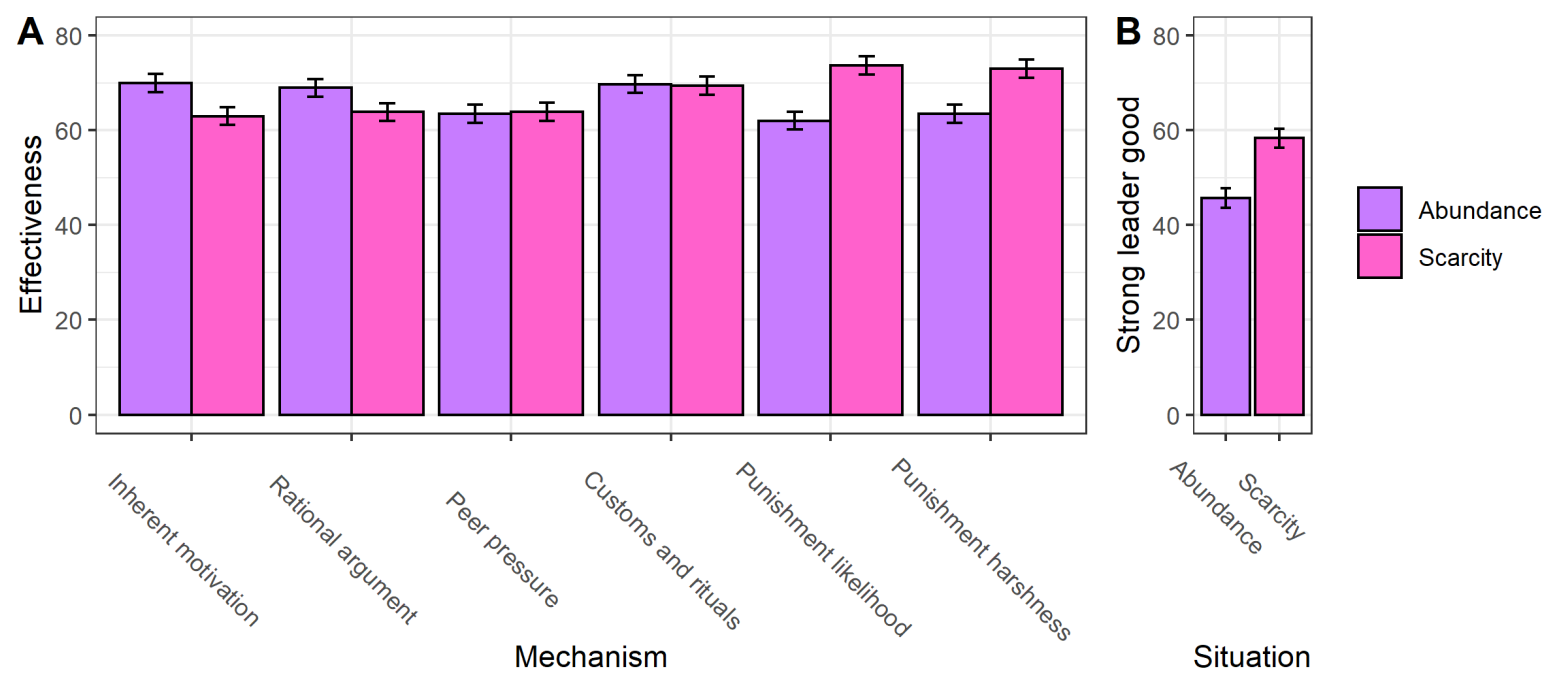

Figure 5. Main experimental results, study 5. A. Rated effectiveness of six influences on compliance with the common-store rules under conditions of abundance and scarcity. B. Ratings of how good it would be for the village if a strong, tough leader were to come along, under abundance and scarcity. Plots show estimated marginal means \pm 1 standard error.

\section{Discussion}

Study 5 replicated a central finding of earlier studies: a strong, tough leader was rated a better thing for a village facing scarcity than abundance. It also shed light on why: under scarcity, our respondents assumed that villagers' inherent motivation to do what is right, and rational argument, would be less effective as sources of compliance with the rules; whilst punishment (both the likelihood and the severity) would become more effective. Approval of a strong leader, both at baseline and in terms of the shift under scarcity, was predicted by ratings of the effectiveness of punishment to improve compliance. This pattern therefore explains why, in study 4 , a strong leader would improve expected moral behaviour only under scarcity and not under abundance. The authoritarian strategy of punishment is less effective under abundance than scarcity, and so the added value of the strong leader is nullified under these circumstances. Meanwhile, other influences such as people's rationality and inherent moral sense, which do not require a strong leader, become more effective, at least compensating the reduced effectiveness of punishment.

The six different influences on compliance were rated roughly equally effective to one another on average. Thus, it appears that our respondents' intuitive theory of social motivation admits of multiple non-exclusive ways that individuals come to do what is right, with no single lever dominant. This intuitive theory is situation-sensitive in a strong way. It is not just that when there is existential threat-scarcity-more levers are required to ensure compliance, whereas under abundance the costliest of these levers can be stood down. Rather, the lever of punishment is seen as less effective when society is living through abundance. Perhaps people intuitively understand that harsh punishments applied when the overall societal situation is benign, and when rational argumentation might achieve the same effect, are likely to be seen as illegitimate, and illegitimate punishment can be not just ineffective but counterproductive (Nugier et al., 2007; Strimling \& Eriksson, 2014).

\section{General Discussion}


We have studied the effects of certain situational features on intuitive social and political judgements. We argued in the Introduction that separate cognitive systems drive intuitions about what political arrangements would be ideal (moral cognition), and what would happen in practice (the intuitive theory of social motivation). The main innovation of the present paper is to have begun to study the computations of the intuitive theory of social motivation, and show how and why these lead to a preference for authoritarian governance under some circumstances. The members of society are intuited to behave on average more morally if society is homogenous, at peace, and blessed with abundant resources, than under other circumstances (study 1). When the situation is more adverse (specifically, under war or resource scarcity), a sub-group of the members of society is predicted to behave less morally and more selfishly (though another sub-group is predicted to do the opposite; study 3). The deterioration of behaviour in the selfish sub-group is experienced as a serious social problem (study 3 ), because societies in which some of the people will not behave morally cannot even approach the social order they should ideally have (study 1 ). These are the fertile grounds for the preference for authoritarian governance to thrive in. Our findings not only support the well-known prior generalization that societal threat increases the preference for authoritarian leaders; they shed light on why this would be the case. Authoritarian leaders intuitively increase citizens' moral compliance exactly when the compliance of a dangerous subset is low due to a threatening situation (study 4). Hence, an authoritarian leader, in these situations, is felt necessary to rescue the social order. This is because when people are faced with adverse situations, they are intuited to respond less strongly to 'higher' interventional levers such as rational persuasion and the inherent motivation to do what is right, and more strongly to the main lever of the authoritarian leader: punishment (study 5).

The principle that tougher governance is needed under certain conditions of threat, in order to maintain the social order, is not just a quirk of our hypothetical experimental judgements. It emerges clearly from survey data from 52 countries (study 2). Moreover, it is reflected in the ethnographic record. Non-industrial societies frequently facing scarcity or war are described as culturally 'tighter' than those that do so less often, where tightness involves strong normative constraints on individual behaviour, enforced through harsh punishment (Jackson et al., 2020). The Turkana of East Africa use harsh punishment to regulate defection during inter-group raiding (Mathew \& Boyd, 2011). Historical North American societies such as the Cheyenne maintained a dual war-peace organization (Gearing, 1962). In peacetime, villages were run by councils, coordinated by peace chiefs, whose functioning was notably participatory and non-coercive. In war time, leadership was ceremonially passed to a different set of war chiefs, chosen for different, more coercive and aggressive styles. As Gearing (1962, p. 53) writes: 'Decision making in [peacetime] councils moved slowly; leisurely discussions continued for days, even weeks.... In war, there was no time to lose. The slow nurturing of consensus was less important than the quick coordination of action. Without time for discussion and with, often, the survival of the war party depending on the correct action from every individual, coercion was functional.' The present research suggests that the need for a situation-specific shift in governance, as implemented by dual war-peace organization, is immediately intuitively obvious even for participants with no familiarity with those societies or their specific histories.

It appears that the intuitive theory of social motivation represents humans who are free from existential threat as a different kind of animal from humans for those who face it: more strongly guided by 'higher' human attributes of morality and reason, less in need of shaping through punishment (study 5). Once we had seen this picture in our data, we found it easy to find it represented elsewhere. For example, Turnbull's famous description of famine amongst the Ik of Uganda contends that under scarcity, 'a much more basic man appears, using much more basic 
survival tactics' than in times of plenty (Turnbull, 1972 p. 32). The evidence that adversity actually causes mass selfishness has been questioned, not just for the Ik context (Heine, 1985), but for the impact of famine (Dirks, 1980) and warfare (Bauer et al., 2016; Bellows \& Miguel, 2009) on human societies more generally. That Turnbull's description became so famous may suggest that it speaks to our vigilant intuitive theory, rather than being an accurate description of actual modal behaviour. Previous research has shown that people use group membership to attribute strangers with different levels of morality (Brambilla et al., 2013; Poppe \& Linssen, 1999), or uniquely human mental characteristics (Leyens et al., 2001). This study is to our knowledge the first evidence that they attribute different levels of morality and uniquely human mental characteristics to the same humans when those humans are facing different situations. We feel this justifies our use of the term 'intuitive theory of social motivation' to the set of judgements we have studied. Participants do not just have a prior about the likely level of moral goodness of unknown humans. Rather, they infer that this level will be different under different circumstances, including circumstances of which they presumably have no direct experience. Moreover, they intuit that different kinds of interventions (punishment rather than persuasion) would be necessary to change behaviour under different circumstances. These are the hallmarks of a theory, intuitive or otherwise: the ability to make predictions for new situations, and to model the effects of different kinds of interventions under different circumstances (Gerstenberg \& Tenenbaum, 2017).

Though many studies have shown correlations between social conditions and authoritarian preferences (like our study 2 here), only experimentation can shed light on how flexible the underlying cognition is. Authoritarian preference could be formed through years of early experience, or cultural transmission of stable norms, or flexible ongoing computations, and the correlational data would still look the same. Studies 1 and 3-5 concur with earlier experimental studies in uncovering considerable situational flexibility in adult judgement (Caluori et al., 2020; Feldman \& Stenner, 1997; Jackson., 2019; Laustsen \& Petersen, 2017; Sprong \& Jetten, 2019). In our experiments, the same person endorsed wildly different prescriptions for governance within a minute or two, merely by being given one or two sentences of new information. This suggests that a substantial component of cross-cultural and historical variation in political ethos could be 'evoked culture' (Tooby \& Cosmides, 1989): the combined output of many people's flexible individual-level cognitive mechanisms, which are receiving different environmental inputs on average in different populations. Evoked culture has the potential to change rapidly as environmental inputs change, producing different expectations about how dynamically societies can respond to circumstance, compared to approaches that stress generation-to-generation social transmission (Mathew \& Perreault, 2015) or early-life programming (Safra et al., 2017). The concept of evoked culture also generates a subtly different framing of cultural and sub-cultural variation than other conceptions of culture (Tooby \& Cosmides, 1989). Rather than certain populations or social groups 'having' one set of attitudes, and others 'having' different ones, all normal humans contain and can compute the full range of possible conclusions about how society should be governed. They differ in which conclusions are currently being evoked by the experiences and inputs they are receiving. A parallel example comes from child discipline in wartime (Malcolm et al., 2020). In communities exposed to warfare, parents discipline their children in more coercive ways. This pattern does not endure for generations, and nor is it dispositional; rather, data from Iraq suggests that coercive discipline waxes and wanes with the local intensity of the fighting threat.

Our studies suffer from a number of limitations. First, the experimental studies, which constitute the distinctive part of this paper and support our major conclusions about the intuitive theory of social motivation, all derive from a single participant pool of UK adults. The finding that war and scarcity are associated with greater authoritarian governance preference is already known to be more 
general, on the evidence of the present study 2 as well as both correlational and experimental data from very different societal contexts (Jackson et al., 2020; Laustsen \& Petersen, 2017). However, the other study variables of expected moral behaviour and achievable redistribution have not yet been studied in other participant pools. Second, our experiments use within-subjects designed. We view this as an asset, since the strongest possible demonstration of situational cognitive flexibility is for the same individual to reach a different view when given new information. However, within-subjects designs do raise the possibility of a particular kind of demand characteristic: the participant sees that something in the materials has changed and therefore feels the need to change their response to show they are attending. The degree of situational responsiveness might therefore be exaggerated compared to what would be observed in more realistic situations. To mitigate this concern, we ran a between-subjects version of one our hypothetical societies experiments in Nettle and Saxe (2020; study 7). The difference in ideal redistribution between two hypothetical villages was comparable in the between-subjects version to the within-subjects version, albeit washed over with a large degree of between-subjects incidental variation that the within-subjects design controls. The observed effects in the present experiments, for example on authoritarian governance preference, are large. Even if real-world situation-driven attitude changes are a fraction of the size, they could have important societal consequences.

The study of the intuitive theory of social motivation is important for social and political life in a number of ways. First, the principles revealed can be important for both predicting and explaining historical changes in popular sentiment, and hence in styles of governance, in different countries. Although countries have long-term cultural patterns of authoritarianism or democracy, they also undergo rapid historical change that is not unidirectional. Mass change in intuitive patterns of cognition, in response to particular experiences or cues, is a potentially important force generating or permitting changes in popular sentiment and hence policy. Second, the particular biases of intuitive theories mean that the most intuitively appealing policy responses to a situation are not always the best ones. We have made this case elsewhere, for the case of social assistance to people with disabilities (Johnson \& Nettle, 2021): the intuitive theory is especially vigilant to cheating (fraudulent claims), and hence politicians are motivated and rewarded for overspending on regulation and verification of eligibility, and underspending on actual help. They treat cheating as the main problem, when the main problem is disability. Likewise, faced with a threatening societal situation requiring collective action (such as a pandemic), we may, because of our intuitive theories, be overly pessimistic about the compliance of our fellow citizens, and hence too focussed on the need for enforcement and punishment, compared to rational argumentation or support. More generally, people who feel under threat may intuitively support increases in punishment severity, despite evidence that this is not effective for deterrence in the way intuition suggests (Dölling et al., 2009; Nagin, 2013).

A final implication of this work is that the source of differing intuitions about how society should be run could often be different appraisals about what situation society faces. That is, liberals and conservatives may have no disagreement about what governance is required for any given situation, but may disagree about which situation currently obtains, the former seeing it as dangerous or threatening, the latter as peaceful or benign (Sibley et al., 2007). The philosopher Thomas Hobbes reached the conclusion that social life could only function if all citizens submitted absolutely to a powerful, punitive sovereign. For Hobbes, the archetypal societal situation, the 'state of nature', was one of constant scarcity and war (Seabright et al., 2020). Given the intuitive theory, it is no surprise he therefore arrived at the conclusion that people would not be moral toward one another unless coerced by a strong leader. Had Hobbes had in mind a state of nature featuring peace and abundance, his conclusions might have been very different. An important locus for mutual 
comprehension and the generation of consensus could be exploration of what each of us believes the present situation of society to be, and how well those beliefs correspond to reality.

\section{References}

Aaroe, L., \& Petersen, M. B. (2014). Crowding out culture: Scandinavians and Americans agree on social welfare in the face of deservingness cues. Journal of Politics, 76(3), 684-697. https://doi.org/10.1017/S002238161400019X

Almås, I., Cappelen, A., \& Tungodden, B. (2020). Cutthroat Capitalism Versus Cuddly Socialism: Are Americans More Meritocratic and Efficiency-Seeking than Scandinavians? Journal of Political Economy, 128.

Bauer, M., Blattman, C., Chytilová, J., Henrich, J., Miguel, E., \& Mitts, T. (2016). Can war foster cooperation? Journal of Economic Perspectives, 30(3), 249-274. https://doi.org/10.1257/jep.30.3.249

Bellows, J., \& Miguel, E. (2009). War and local collective action in Sierra Leone. Journal of Public Economics, 93(11-12), 1144-1157. https://doi.org/10.1016/j.jpubeco.2009.07.012

Brambilla, M., Hewstone, M., \& Colucci, F. P. (2013). Enhancing moral virtues: Increased perceived outgroup morality as a mediator of intergroup contact effects. Group Processes and Intergroup Relations, 16(5), 648-657. https://doi.org/10.1177/1368430212471737

Caluori, N., Jackson, J. C., Gray, K., \& Gelfand, M. (2020). Conflict Changes How People View God. Psychological Science. https://doi.org/10.1177/0956797619895286

Cohen, J. (1988). Statistical Power Analysis for the Behavioral Sciences (2nd editio). Lawrence Erlbaum Associates.

Dirks, R. (1980). Social Responses During Severe Food Shortages and Famine [and Comments and Reply]. Current Anthropology, 21, 21-44. https://doi.org/10.1086/202399

Dölling, D., Entorf, H., Hermann, D., \& Rupp, T. (2009). Is deterrence effective? results of a metaanalysis of punishment. European Journal on Criminal Policy and Research, 15, 201-224. https://doi.org/10.1007/s10610-008-9097-0

Doty, R. M., Peterson, B. E., \& Winter, D. G. (1991). Threat and Authoritarianism in the United States, 1978-1987. Journal of Personality and Social Psychology, 61(4), 629-640. https://doi.org/10.1037/0022-3514.61.4.629

Drazanova, L. (2020). Introducing the Historical Index of Ethnic Fractionalization (HIEF) Dataset: Accounting for Longitudinal Changes in Ethnic Diversity. Journal of Open Humanities Data, 6, 18. https://doi.org/10.5334/johd.16

Duckitt, J., Bizumic, B., Krauss, S. W., \& Heled, E. (2010). A tripartite approach to right-wing authoritarianism: The authoritarianism-conservatism-traditionalism model. Political Psychology, 31(5), 685-715. https://doi.org/10.1111/j.1467-9221.2010.00781.x

Duckitt, J., \& Fisher, K. (2003). The impact of social threat on worldview and ideological attitudes. Political Psychology, 24(1), 199-222. https://doi.org/10.1111/0162-895X.00322

Feldman, S., \& Stenner, K. (1997). Perceived threat and authoritarianism. Political Psychology, 18(4), 741-770. https://doi.org/10.1111/0162-895X.00077

Fog, A. (2019). Evolutionary theories of authoritarianism. A test and comparison of alternative theories. https://www.researchgate.net/publication/331975968_Evolutionary_theories_of_authoritaria 
nism_A_test_and_comparison_of_alternative_theories

Gearing, F. (1962). Priest and Warriors. Social Structure for Cherokee Politics in the 18th Century. American Anthropological Association.

Gerstenberg, T., \& Tenenbaum, J. B. (2017). Intuitive Theories. The Oxford Handbook of Causal Reasoning. https://doi.org/10.1093/oxfordhb/9780199399550.013.28

Gneezy, A., \& Fessler, D. M. T. (2012). Conflict, sticks and carrots: War increases prosocial punishments and rewards. Proceedings of the Royal Society B: Biological Sciences, 279(1727), 219-223. https://doi.org/10.1098/rspb.2011.0805

Haselton, M. G., \& Nettle, D. (2006). The paranoid optimist: an integrative evolutionary model of cognitive biases. Personality and Social Psychology Review : An Official Journal of the Society for Personality and Social Psychology, Inc, 10(1), 47-66. https://doi.org/10.1207/s15327957pspr1001_3

Häusser, J. A., Stahlecker, C., Mojzisch, A., Leder, J., Van Lange, P. A. M., \& Faber, N. S. (2019). Acute hunger does not always undermine prosociality. Nature Communications, 10(1), 1-10. https://doi.org/10.1038/s41467-019-12579-7

Heine, B. (1985). The Mountain People: Some Notes on the Ik of North-Eastern Uganda. Africa, 55, 3-16.

Ho, A. K., Sidanius, J., Kteily, N., Sheehy-Skeffington, J., Pratto, F., Henkel, K. E., Foels, R., \& Stewart, A. L. (2015). The Nature of Social Dominance Orientation: Theorizing and Measuring Preferences for Intergroup Inequality Using the New SDO7 Scale. Journal of Personality and Social Psychology, 109, 1003-1028. https://doi.org/10.1037/pspi0000033

Inglehart, R. C., Haerpfer, A., Moreno, C., Welzel, K., Kizilova, J., Diez-Medrano, M., Lagos, P., Norris, E., Ponarin, E., \& Puranen, B. (2014). World Values Survey: Round Six - Country-Pooled Datafile. www.worldvaluessurvey.org/WVSDocumentationWV6.jsp

International Monetary Fund. (2021). World Economic Outlook Database. https://www.imf.org/en/Publications/WEO/weo-database/2021/April

Jackson., J. C. (2019). Ecological and cultural factors underlying the global distribution of prejudice. PLOS ONE, 14, e0221953.

Jackson, J. C., Gelfand, M., \& Ember, C. R. (2020). A global analysis of cultural tightness in nonindustrial societies: Tightness in Non-Industrial Societies. Proceedings of the Royal Society B: Biological Sciences, 287(1930). https://doi.org/10.1098/rspb.2020.1036rspb20201036

Jetten, J., Mols, F., \& Postmes, T. (2015). Relative deprivation and relative wealth enhances antiimmigrant sentiments: The vcurve re-examined. PLOS ONE, 10(10), 1-24. https://doi.org/10.1371/journal.pone.0139156

Johnson, E., \& Nettle, D. (2021). Fairness, generosity and conditionality in the welfare system: the case of UK disability benefits. Global Discourse, 1-18. https://doi.org/10.1332/204378920x15989751152011

Kakkar, H., \& Sivanathan, N. (2017). When the appeal of a dominant leader is greater than a prestige leader. Proceedings of the National Academy of Sciences of the United States of America, 114(26), 6734-6739. https://doi.org/10.1073/pnas.1617711114

Kasza, G. J. (2006). War and welfare policy in Japan. The Journal of Asian Studies, 61, 417-435. https://doi.org/10.2307/2700296 
Klein, N., \& Epley, N. (2016). Maybe holier, but definitely less evil, than you: Bounded selfrighteousness in social judgment. Journal of Personality and Social Psychology, 110, 660-674. https://doi.org/10.1037/pspa0000050

Kuznetsova, A., Brockhoff, P. B., \& Christensen, R. H. B. (2017). ImerTest Package: Tests in Linear Mixed Effects Models. Journal of Statistical Software, 82(13).

https://doi.org/10.18637/jss.v082.i13

Laustsen, L., \& Petersen, M. B. (2015). Does a competent leader make a good friend? Conflict, ideology and the psychologies of friendship and followership. Evolution and Human Behavior, 36(4), 286-293. https://doi.org/10.1016/j.evolhumbehav.2015.01.001

Laustsen, L., \& Petersen, M. B. (2017). Perceived Conflict and Leader Dominance: Individual and Contextual Factors Behind Preferences for Dominant Leaders. Political Psychology, 38(6), 10831101. https://doi.org/10.1111/pops.12403

Leyens, J. P., Rodriguez-Perez, A., Rodriguez-Torres, R., Gaunt, R., Paladino, M. P., Vaes, J., \& Demoulin, S. (2001). Psychological essentialism and the differential attribution of uniquely human emotions to ingroups and outgroups. European Journal of Social Psychology, 31, 395411. https://doi.org/10.1002/ejsp.50

Little, A. C., Roberts, S. C., Jones, B. C., \& DeBruine, L. M. (2012). The perception of attractiveness and trustworthiness in male faces affects hypothetical voting decisions differently in wartime and peacetime scenarios. Quarterly Journal of Experimental Psychology, 65(10), 2018-2032. https://doi.org/10.1080/17470218.2012.677048

Malcolm, M., Diwakar, V., \& Naufal, G. (2020). Child discipline in times of conflict. Journal of Conflict Resolution, 64, 1070-1094. https://doi.org/10.1177/0022002719887492

Mathew, S., \& Boyd, R. (2011). Punishment sustains large-scale cooperation in prestate warfare. Proceedings of the National Academy of Sciences of the United States of America, 108(28), 11375-11380. https://doi.org/10.1073/pnas.1105604108

Mathew, S., \& Perreault, C. (2015). Behavioural variation in 172 small-scale societies indicates that social learning is the main mode of human adaptation. Proceedings of the Royal Society $B$ : Biological Sciences, 282(1810), 20150061. https://doi.org/10.1098/rspb.2015.0061

McClintock, C. G. (1972). Social motivation-A set of propositions. Behavioral Science, 17, 438-.

Nagin, D. S. (2013). Deterrence: A Review of the Evidence by a Criminologist for Economists. Annual Review of Economics, 5(1), 83-105. https://doi.org/10.1146/annurev-economics-072412131310

Nettle, D., Johnson, E., Johnson, M., \& Saxe, R. (2021). Why has the COVID-19 pandemic increased support for Universal Basic Income ? Humanities and Social Sciences Communications, 8, 79. https://doi.org/10.31234/osf.io/csr3u

Nettle, D., \& Saxe, R. (2020). Preferences for redistribution are sensitive to perceived luck, social homogeneity, war and scarcity. Cognition, 198, 104234.

Nugier, A., Niedenthal, P. M., Brauer, M., \& Chekroun, P. (2007). Moral and angry emotions provoked by informal social control. Cognition and Emotion, 21(8), 1699-1720. https://doi.org/10.1080/02699930601124738

Obinger, H., \& Schmitt, C. (2019). World war and welfare legislation in western countries. Journal of European Social Policy. https://doi.org/10.1177/0958928719892852

Piff, P. K., Wiwad, D., Robinson, A. R., Aknin, L. B., Mercier, B., \& Shariff, A. (2020). Shifting 
attributions for poverty motivates opposition to inequality and enhances egalitarianism. Nature Human Behaviour. https://doi.org/10.1038/s41562-020-0835-8

Poppe, E., \& Linssen, H. (1999). In-group favouritism and the reflection of realistic dimensions of difference between national states in Central and Eastern European nationality stereotypes. British Journal of Social Psychology, 38(1), 85-102. https://doi.org/10.1348/014466699164059

R Core Development Team. (2020). R: A Language and Environment for Statistical Computing (4.01). $R$ Foundation for Statistical Computing.

Safra, L., Algan, Y., Tecu, T., Grèzes, J., Baumard, N., \& Chevallier, C. (2017). Childhood harshness predicts long-lasting leader preferences. Evolution and Human Behavior, 38(5), 645-651. https://doi.org/10.1016/j.evolhumbehav.2017.05.001

Seabright, P., Stieglitz, J., \& Straeten, K. Van Der. (2020). Evaluating social contract theory in the light of evolutionary social science . *. 1-40. https://doi.org/10.1017/ehs.2021.4

Sibley, C. G., Wilson, M. S., \& Duckitt, J. (2007). Effects of dangerous and competitive worldviews on right-wing authoritarianism and social dominance orientation over a five-month period. Political Psychology, 28(3), 357-371. https://doi.org/10.1111/j.1467-9221.2007.00572.x

Sprong, S., \& Jetten, J. (2019). "Our Country Needs a Strong Leader Right Now": Economic Inequality Enhances the Wish for a Strong Leader. Psychological Science, 1-13. https://doi.org/10.1177/0956797619875472

Strimling, P., \& Eriksson, K. (2014). Regulating the regulation: Norms about punishment. In P. A. M. van Lange, B. Rockenbach, \& T. Yamagishi (Eds.), Social dilemmas: New perspectives on reward and punishment. (pp. 52-69). Oxford University Press. https://doi.org/10.1093/acprof:oso/9780199300730.003.0004

Tingley, D., Yamamoto, T., Hirose, K., Keele, L., \& Imai, K. (2014). Mediation: R package for causal mediation analysis. Journal of Statistical Software, 59(5), 1-38. https://doi.org/10.18637/jss.v059.i05

Tooby, J., \& Cosmides, L. (1989). Evolutionary psychology and the generation of culture, part I. Ethology and Sociobiology, 10(1-3), 29-49. https://doi.org/10.1016/0162-3095(89)90012-5

Turnbull, C. M. (1972). The Mountain People. Jonathan Cape.

van de Pol, M., \& Wright, J. (2009). A simple method for distinguishing within- versus betweensubject effects using mixed models. Animal Behaviour, 77(3), 753-758. https://doi.org/10.1016/j.anbehav.2008.11.006

\section{Contributions}

Contributed to conception and design: DN, RS

Contributed to acquisition of data: DN

Contributed to analysis and interpretation of data: DN, RS

Drafted and/or revised the article: DN, RS

Approved the submitted version for publication: DN, RS

\section{Funding information}


This project has received funding from the European Research Council (ERC) under the European Union's Horizon 2020 research and innovation programme (grant agreement No AdG 666669, COMSTAR).

\section{Competing interests}

The authors declare that they have no competing interests.

\section{Data accessibility statement}

All the stimuli, presentation materials, pre-registrations, participant data, and analysis scripts can be found on this project's page on the Open Science Framework Data (https://osf.io/53yr8/). 